University of Nebraska - Lincoln

DigitalCommons@University of Nebraska - Lincoln

January 2005

\title{
LARVAL DESCRIPTIONS OF EIGHT SPECIES OF MEGASOMA \\ KIRBY (COLEOPTERA: SCARABAEIDAE: DYNASTINAE) WITH A KEY FOR IDENTIFICATION AND NOTES ON BIOLOGY
}

\author{
Brett C. Ratcliffe \\ University of Nebraska-Lincoln, bratcliffe1@unl.edu \\ Miguel Angel Morón \\ Instituto de Ecologia, Veracruz, Mexico, moron_ma@ecologia.edu.mx
}

Follow this and additional works at: https://digitalcommons.unl.edu/entomologypapers

Part of the Entomology Commons

Ratcliffe, Brett C. and Morón, Miguel Angel, "LARVAL DESCRIPTIONS OF EIGHT SPECIES OF MEGASOMA KIRBY (COLEOPTERA: SCARABAEIDAE: DYNASTINAE) WITH A KEY FOR IDENTIFICATION AND NOTES ON BIOLOGY" (2005). Papers in Entomology. 32.

https://digitalcommons.unl.edu/entomologypapers/32

This Article is brought to you for free and open access by the Museum, University of Nebraska State at DigitalCommons@University of Nebraska - Lincoln. It has been accepted for inclusion in Papers in Entomology by an authorized administrator of DigitalCommons@University of Nebraska - Lincoln. 


\title{
Larval Descriptions of Eight Species of Megasoma Kirby (Coleoptera: Scarabaeidae: Dynastinae) with a Key for Identification and Notes on Biology
}

\author{
BRETT C. RATCLIFFE \\ Systematics Research Collections \\ W436 Nebraska Hall \\ University of Nebraska State Museum \\ Lincoln, NE 68588-0514, U.S.A. \\ bratcliffe1@unl.edu
}

AND

Miguel-Angel Morón

Departamento de Entomología

Instituto de Ecologia, A. C. (Sector SEP-CONACYT)

Apartado Postal 63, 91000 Xalapa, Veracruz, MEXICO

moron_ma@ecologia.edu.mx

\begin{abstract}
The third instar larvae of Megasoma pachecoi Cartwright, M. punctulatus Hardy, M. thersites LeConte, M. vogti Cartwright, $M$. cedrosa Hardy, M. elephas (F.), M. actaeon (L.), and M. occidentalis Bolívar y Pieltain, Jiménez-Asúa, and Martínez are described. Preliminary diagnosis for the larvae of Megasoma species from North and Central America and a key to eight species are presented. Comparative, brief descriptions of first and second instar larvae of M. elephas, $M$. thersites, $M$. pachecoi, and $M$. cedrosa, and a detailed description of the male pupa of $M$. elephas, are also included. Diagnostic structures of immatures are illustrated. Notes on the habits, biology, and distribution of the eight species are reviewed.
\end{abstract}

\section{Resumen}

Se describen las larvas de tercer estadio de Megasoma pachecoi Cartwright, M. punctulatus Hardy, M. thersites LeConte, M. vogti Cartwright, M. cedrosa Hardy, M. elephas (F.), M. actaeon (L.), y $M$. occidentalis Bolívar y Pieltain, Jiménez-Asua y Martínez. Se presenta una diagnosis preliminar para las especies de Megasoma en Norte y Centroamérica, incluyendo una clave para separar las larvas de las ocho especies mencionadas. Se agregan breves descripciones comparativas del primero y segundo estadio larvario de $M$. elephas, $M$. thersites, $M$. pachecoi y $M$. cedrosa, y también una descripción detallada de la pupa de un macho de $M$. elephas. Se ilustran las estructuras diagnósticas de éstos estadios inmaduros, y se incorporan notas y comentarios sobre los hábitos, biología, y distribución de las ocho especies citadas.

The genus Megasoma Kirby consists of 14 species of moderately-sized to very large beetles in the tribe Dynastini. They are collectively known as "elephant beetles" because the size of several species in Central and South America are very large, $c a .10$ $\mathrm{cm}$. Species in the genus are found from the southwestern United States to northern Argentina. Four species are found only in South America, seven species are found in northern Mexico and the southwestern United States, and the remaining three species occur in southern Mexico and Central and South America. The Mexican Megasoma 
occidentalis Bolívar y Pieltain, Jiménez-Asúa, and Martínez was recently elevated to species status by Morón and Gòmez-Anaya (2002).

Adults of Megasoma are recognized by their moderate to large size, broadly truncate to emarginate clypeal apex with acute or toothed anterior angles, mandibles with two or three acute teeth, short prosternal process, and tridentate anterior tibia. Males all have a variably developed, bifurcate head horn, and the pronotum is either armed or not. Hardy (1972) reviewed the North and Central American species, Endrödi (1977, 1985) provided a synopsis of all the species, and Lachaume (1985) illustrated (life-size) all the species as part of the Sciences Nat Beetles of the World series.

The immature stages, biology, and life cycle of the species of Megasoma species are poorly known. Some comments and photographs about collecting larvae of M. actaeon (L.) inside the standing trunk of the "matamatá" tree, Lecythis chartacea Berg, (Myrtaceae), in the Brazilian Amazon were published by Zahl (1959). Gibson (1964) published some data on the habits and larval development of $M$. pachecoi Cartwright that were reared from eggs laid by captive females that were collected on the branches of "palo brea," Cercidium torreyanum (Wats.) Sarg. (Caesalpinaceae). Möhres-Reitter (1966) provided a short note and picture of the larva of M. gyas (Herbst) in Brazil, and he indicated Cordia gerascanthus L. (Boraginaceae; "palo de rosa") was the rotting tree in which the larvae were found. William Warner (pers. comm., to BCR) indicated that adult females of $M$. sleeperi Hardy occasionally come to lights (males rarely so), and that males can be found on the trunks of blue palo verde, Cercidium floridum Benth. (Caesalpinaceae), at night or on small branches feeding from dawn to $\mathrm{ca}$. $0900 \mathrm{~h}$. Adults have also been observed emerging from the sand beneath palo verde trees at dusk. Morón (1977) provided a description of the third-stage larva of $M$. occidentalis that was found in the rotten stem of a coconut palm, Cocos nucifera L. (Arecaceae). Life cycle notes and illustrations of immature stages of M. elephas (F.) reared in captivity were provided by Morón (1984), Morón et al. (1997), and Morón and Deloya (2001).

Fourteen species of Megasoma are distributed from the southwestern United States to northern Argentina (Endrödi 1985). One of us (BCR) was able to obtain over the last five years the larvae of six species of Megasoma from the southwestern United States, northwestern Mexico, and South America that provided the foundation for this work. MAM obtained the larvae of two additional species. In this paper we describe for the first time the third-instar larvae of $M$. pachecoi Cartwright, M. punctulatus Hardy, M. thersites LeConte., M. vogti Cartwright, M. cedrosa Hardy, M. actaeon (L.), and M. elephas (F.), as well as a redescription of the third-instar larva of M. occidentalis Bolívar y Pieltain, Jiménez-Asúa and Martínez. We also have notes on the first and second instars of M. elephas and describe the pupa. Megasoma species for which the immature stages have not been discovered and/or described are M. gyas (Herbst), M. mars (Reiche), M. anubis (Chevrolat), M. joergenseni (Bruch) (all South American), M. sleeperi Hardy (SW United States), and M. lecontei Hardy (Baja California Sur, Mexico).

Terms and characters used in the descriptions are those of Ritcher (1966), Ratcliffe and Chalumeau (1980), Morón (1977, 1987, 1993, 1995), and Morón and Ratcliffe (1990). Drawings were made using a stereomicroscope and camera lucida. Measurements were obtained with an ocular micrometer or caliper. Study specimens were deposited at the University of Nebraska State Museum, Lincoln, Nebraska (UNSM) and the Instituto de Ecología, Xalapa, Veracruz, Mexico (IEXA).

\section{Diagnosis for the Larvae of the Genus Megasoma}

Head capsule dark brown to nearly black. Cranium densely punctate. Labrum slightly asymmetrical. Epipharynx with raised haptomerum, without heli, pedium wide, epitorma 
vague, crepis not well-defined. Right mandible with 2 scissorial teeth, 1 pre-scissorial tooth, and 3 molar lobes. Left mandible with 2 scissorial teeth, 1 prescissorial tooth, 2 molar lobes and long, truncate acia. Stridulatory areas of both mandibles well-marked by 22-40 fine striae. Galea and lacinia fused into mala, apex of galea with 1 uncus, apex of lacinia with 3 unci fused at their bases. Hypopharynx with right anterolateral process of hypopharyngeal sclerome developed as more or less raised, rounded tooth. Last antennal segment with 4-14 dorsal sensory spots. Pronotal lateral scleromes irregularly shaped with transverse row of slender setae. Tarsunguli with 2 internal, long, thick, basal setae and 2 external, long, thick preapical setae (except $M$. actaeon with 1 internal basal seta and 1 external preapical seta). Raster without pallidia and septula. Body vestiture usually abundant. Third instar larvae with maximum width of head capsule 7.3-17.2 $\mathrm{mm}$ and approximate dorsal body length of 64 to $225 \mathrm{~mm}$.

\section{Megasoma pachecoi Cartwright, 3rd instar}

(Figs. 1-15)

Description based on remnants of two third instar larvae reared from eggs laid in captivity by females collected in Mexico: State of Sonora, near Ciudad Obregón, IX / X- 1964 on branches of Cercidium torreyanum, 120 m, W.W. Gibson collector (UNSM, IEXA).

Description. Head. Maximum width of head capsule $11.3 \mathrm{~mm}$. Surface of cranium densely punctate, dark brown. Frons (Fig. 1) on each side bearing 1 posterior frontal setae, 7 anterior frontal setae, and 2 anterior angle frontal setae; remaining cranial surface with 4 dorsoepicranial setae, 1 epicranial seta, and 5-6 paraocellar setae at each side. Clypeus with 2 lateral setae on each side. Labrum slightly asymmetrical, ovate, with 3-4 posterior setae, 2 central setae, and 2 lateral setae. Ocelli not evident. Epipharynx (Fig. 2) with fused zygum and epizygum forming oblique, raised, sclerotized tubercle on haptomerum; heli and plegmatia absent; right chaetoparia with 42-47 spinelike setae and 60-65 sensillae toward the gymnoparia; left chaetoparia with 56-60 spine-like setae and 52-58 sensillae; acroparia with 6-7 straight, long, thick setae toward right side and 10-12 medium size, slender setae toward left side; right acanthoparia with 9-10 short, curved, spine-like setae; left acanthoparia with 13-14 short, curved, spine-like setae; pedium wide, epitorma vague; dexiotorma long, narrow, with acute inner side; laeotorma shortened, with wide, rounded pternotorma; dexiophoba sparse, formed by 4-6 setae; laeophoba well-developed between haptolachus and inner side of laeotorma, formed by 12-17 setae; sclerotized plate of right nesium large, elongate, transversal; sense cone on left nesium represented by large, longitudinal, wellsclerotized plate; crepis not defined. Scissorial area of right mandible (Fig. 3) slightly abraded, with 2 large, wide teeth, well-separated by notches, and 1 basal, small tooth; molar area with 3 lobes, brustia sparse. Scissorial area of left mandible (Fig. 4) slightly abraded, with 2 well-marked, large teeth and 1 rounded pre-incisor tooth; molar area with 2 wide lobes, sparse brustia and long, truncate acia. Stridulatory area of each mandible well-marked by 30-32 fine striae. Mala (Fig. 5) with apical uncus of galea well-developed and 3 conical unci fused at their bases at apex of lacinia (Fig. 6); maxillary stridulatory area (Fig. 7) with 8 small, subtrapezoidal, rounded or truncated teeth and wide, truncate anterior process. Labium with numerous long, strong setae located principally at sides; hypopharynx with right anterior lateral process of hypopharyngeal sclerome strongly developed, raised and curved, heavily sclerotized; left hypopharyngeal lateral lobe with patch of 1012 posterior lateral setae (Fig. 5). Last antennal segment on dorsal surface (Fig. 8) with 10-14 sensory spots; ventral surface with 10-12 spots (Fig. 9). Thorax. Pronotum with wide, irregular, reddish brown lateral scleromes and 1 transverse row of 32 long, slender setae. Meso- and metanotum each with scattered, long, slender setae at middle and 30 setae on each side. Thoracic spiracles $1.3 \mathrm{~mm}$ long and $2.0 \mathrm{~mm}$ wide; lobes of respiratory plate contiguous, directed posteriorly. Spiracular bulla prominent, transverse, with acute, erect process. Tarsal claws or tarsunguli (Figs. 10-11) similar on all legs, with acute apex, each bearing 2 internal, long, thick, basal setae and 2 external, long, thick, preapical setae. Abdomen. Dorsa of segments I-VI each with 2-4 transverse rows of 20-36 long, slender setae and 3-5 transverse rows of 40-65 short, spine-like setae. Dorsa of segments VII-VIII with 3-4 rows of 20-28 long, slender setae and 4-6 rows of 40-46 short, spine- 

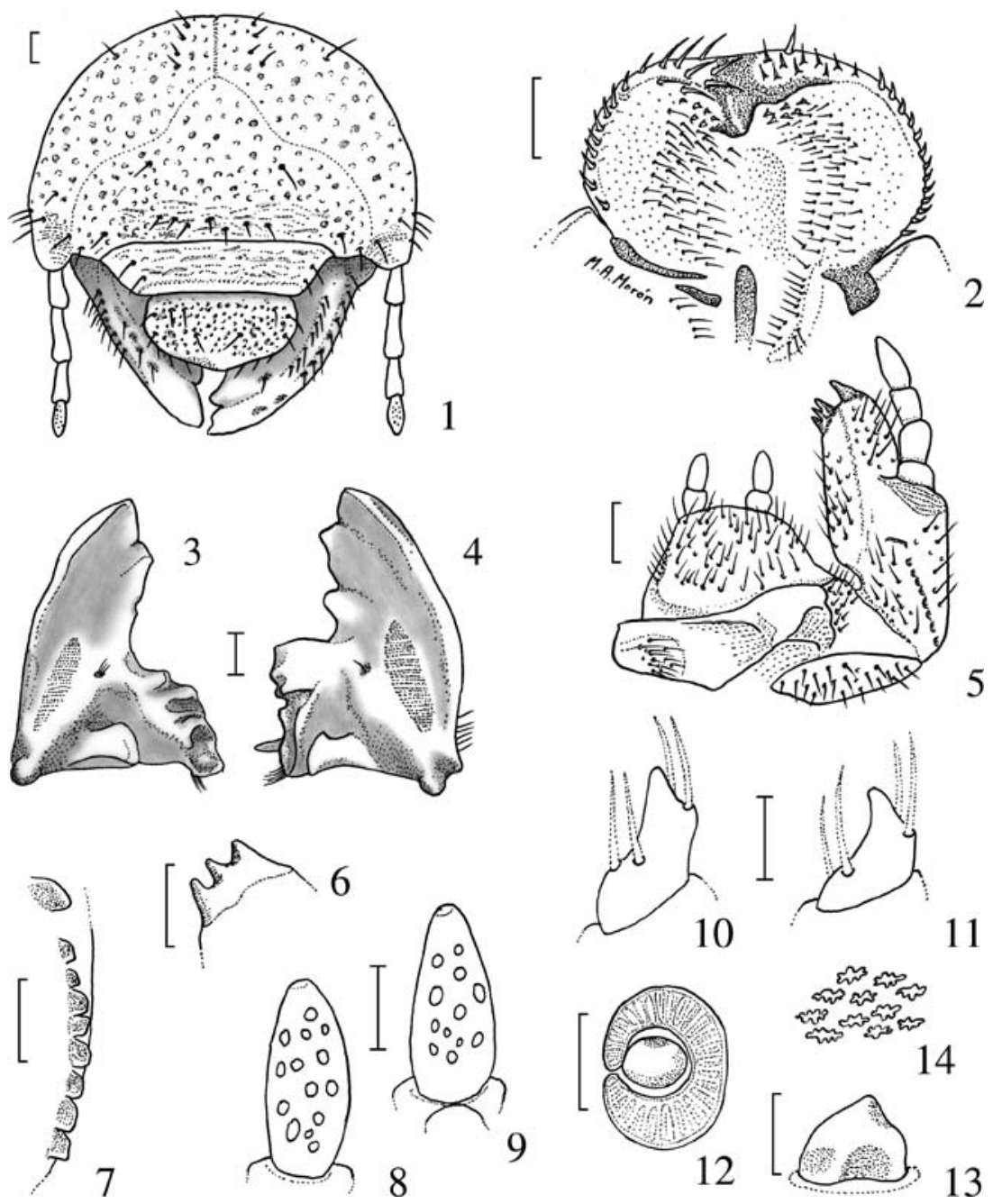

Figs. 1-14. Megasoma pachecoi, third instar. 1) Head, frontal view; 2) epipharynx; 3-4) mandibles, ventral view, 3) right and 4) left; 5) right maxilla and hypopharynx, dorsal view; 6) detail of unci of lacinia; 7) detail of maxillary stridulatory area; 8-9) distal segment of antenna, 8) dorsal view and 9) ventral view; 10-11) left tarsal claws, external views, 10) middle and 11) posterior; 12) second left abdominal spiracle; 13) detail of bulla of spiracle, ventral view; 14) microstructure of respiratory plate $(500 \times)$. Figs. $1-5$, bar $=1 \mathrm{~mm}$. Figs. $6-13$, bar $=0.5 \mathrm{~mm}$.

like setae. Dorsum of segment IX with scattered, short, spine-like setae in anterior half and 50-60 long, slender, setae on sides where cuticle is slightly rugose. Dorsum of segment X with 60-65 short, spine-like setae and 40-45 long, slender setae on each side. Venter of abdominal segments I-IX each with 1 median, transverse row of long setae. Raster without pallidia and septula, with 8 long setae in campus, teges formed by 50 setae; cuticle longitudinally rugose. Lower anal lip with 110-120 short, spine-like setae and 5-7 medium size, erect setae. Upper anal lip with 120-130 short, spine-like setae. Spiracles of segments I-VIII progressively larger (1.5-1.8 mm wide; $1.1-1.4 \mathrm{~mm}$ long), lobes 


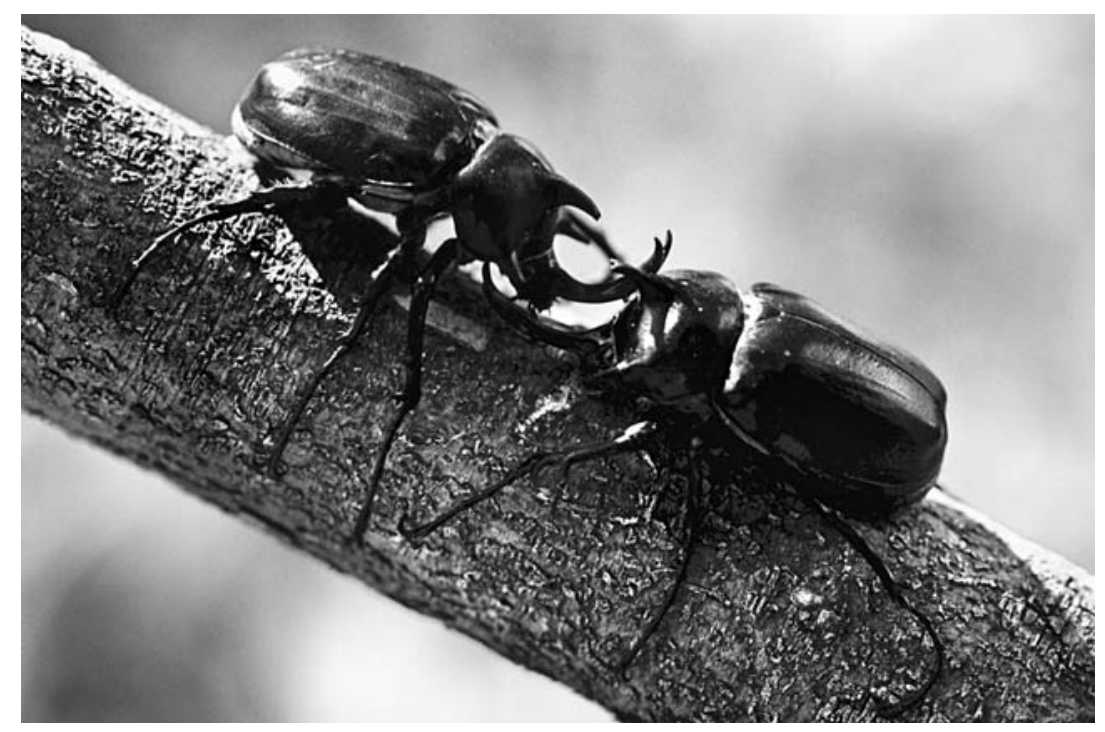

Fig. 15. Megasoma pachecoi, males fighting on branch of Cercidium torreyanum. Tezopaco, Sonora, Mexico. August 1998. Photo by G. Nogueira.

of respiratory plates contiguous (Fig. 12), directed forward. Spiracular bulla prominent, transverse, with acute, erect process (Fig. 13); respiratory plate with 47-54 irregularly-shaped holes (Fig. 14) across any diameter. Approximate dorsal body length not measurable.

First-instar Larva. Based on one first-instar larva reared from egg laid by female collected in México: Sonora, Tezopaco, 10-IX-2002, G. Nogueira, fixed at 18 days age (IEXA).

Description. Similar to third-instar larva except as follows: maximum width of head capsule $2.8 \mathrm{~mm}$. Epicranium and frons with many long, slender setae. Last antennal segment with 5-6 dorsal sensory spots. Sclerotized plates on sides of pronotum absent. Eclosion spine on each side of metanotum small, narrow, conical, with acute apex. Thoracic spiracles $0.12 \mathrm{~mm}$ wide, $0.11 \mathrm{~mm}$ long. Abdominal spiracles kidney-shaped, similar in size: $0.12 \mathrm{~mm}$ wide, $0.10 \mathrm{~mm}$ long, without definite bulla. Approximate dorsal body length $12 \mathrm{~mm}$.

Remarks. Larvae of $M$. pachecoi share many characters with the larvae of M. elephas such as: 4 dorsoepicranial setae, 2 lateral clypeal setae, rounded pternotorma, 8 maxillary stridulatory teeth, acanthoparia with 8-10 setae, spine-like setae on dorsum of second abdominal segment, abdominal spiracles progressively longer from segments I-VIII, and lobes of respiratory plates of spiracles contiguous. However, in M. pachecoi the structure of the prominent, raised, acute bulla, 10-14 dorsal sensory spots on the last antennal segment, reduced number of setae on the right chaetoparia, labrum, epicranium and frons, as well as the head and body size, separate the larvae of these species.

Distribution and Habits. Adults of M. pachecoi have been collected in thorn bush and deciduous tropical forests located between 100 to 500 meters elevation at the southern borders of the Sonoran desert, from Esperanza east to Tezopaco, Hornos, Ciudad Obregón, Valle del Yaqui and Navojoa (all state of Sonora), then south to El Carrizo and 35 mi N Los Mochis (state of Sinaloa), México (Cartwright 1963; Gibson 1964). Adults are crepuscular and are attracted to electric lights, but during the day, 
usually under very hot conditions [more than $42^{\circ} \mathrm{C}$ ]), they are active on the branches of "palo brea," (Cercidium torreyanum (Wats.) Sarg., Caesalpinaceae), or "huacaporo," (Parkinsonia aculeata L., Caesalpinaceae). Adults are active between August and October and feed on the cambium or waxy secretions of the branches. Males frequently engage in combat (Fig. 15), pushing and shoving with their horns on the same branch for some minutes until one abandons the site (G. Nogueira, pers. comm., to MAM). Gibson (1964) found larvae inside unidentified, rotten stumps and in the soil of an old corral. He also reared larvae and adults from eggs laid by females in captivity that, together with males, were collected between mid-September to mid-October and maintained in cages with overripe bananas. Copulation lasted at least 15 minutes, and females began to oviposit immediately thereafter. Females from the field contained 1-23 eggs, and the average was 13 . The pearly, oval eggs, averaging $4.4 \times 2.9 \mathrm{~mm}$ in size, were laid singly in galleries excavated in compost supplied to the females. Eggs laid in late September hatched in 29 days (average) whereas those laid in mid-October hatched in 37 days (average). Larvae were $8 \mathrm{~mm}$ in length at eclosion and grew about $1.5 \mathrm{~mm}$ per week on a diet of compost and rotten wood. They seemed tolerant of a lack of food and water. A few $80 \mathrm{~mm}$ long larvae pupated at ten months of age and emerged after three weeks pupation as undersized adults. The remaining larvae needed at least two years to complete their life cycle (Gibson 1964).

\section{Megasoma punctulatus Cartwright, 3rd instar}

(Figs. 16-28)

Description based on two third instar larvae reared from eggs laid by female collected in U.S.A., Arizona, Santa Cruz Co. 6.5 mi E Hwy 82 on Duquesne Rd., 4-VIII-1997, preserved last week of VIII-1998, W.B. Warner (UNSM, IEXA).

Description. Head. Maximum width of head capsule $7.6 \mathrm{~mm}$. Surface of cranium densely punctate, dark brown. Frons (Fig. 16) on each side with 6-7 posterior frontal setae, anterior frontal setae absent, 7-8 exterior frontal setae, and 3-5 anterior angle frontal setae; remaining cranial surface with 2-3 dorsoepicranial setae, 40-46 epicranial setae, and 6-7 paraocellar setae on each side. Clypeus with 3 lateral setae on each side. Labrum slightly asymmetrical, ovate, with 4-5 posterior setae, 2 central setae, and 2-3 lateral setae. Ocelli not evident. Epipharynx (Fig. 17) with fused zygum and epizygum forming oblique, raised, subconical, well-sclerotized tubercle on haptomerum; heli and plegmatia absent; right chaetoparia with 46-48 spine-like setae and 18-20 sensillae toward gymnoparia; left chaetoparia with 80-88 spine-like setae and 8-10 sensillae; acroparia with 10-11 straight, long, thick setae toward right side and 12-15 straight, long, thick setae toward left side; right acanthoparia with 8 short, curved, spine-like setae; left acanthoparia with 9 short, curved, spine-like setae; pedium wide, epitorma vague; dexiotorma long, narrowed toward left nesium, with rounded inner side; laeotorma narrowed, diffuse, with wide, rounded pternotorma; dexiophoba sparse, formed by 7-8 setae; laeophoba sparse with 7-10 setae between haptolachus and inner side of laeotorma; sclerotized plate or right nesium large, subtriangular; sense cone on left nesium represented by large, wide, longitudinal, well-sclerotized plate; crepis partially defined at right side and vaguely marked on left side. Scissorial area of right mandible (Figs. 18, 20) slightly abraded, with 3 large, wide teeth, well-separated by notches, and 1 basal, small tooth; molar area with 3 lobes, brustia sparse. Scissorial area of left mandible (Figs. 19, 21) not abraded, with 2 well-marked, large teeth and 1 subtriangular, pre-incisor tooth; molar area with 2 wide lobes, sparse brustia and long, acute acia. Stridulatory area of each mandible well-marked by 23-25 fine striae. Mala (Fig. 22) with apical uncus of galea welldeveloped, and 3 conical unci fused at their bases at apex of lacinia; maxillary stridulatory area with 7 small, subtrapezoidal, rounded teeth and wide, truncate anterior process. Labium with numerous long, strong setae located near sides and short, spine-like setae at middle; hypopharynx with right anterior lateral process of hypopharyngeal sclerome strongly developed, raised and curved, heavily sclerotized; left hypopharyngeal lateral lobe with patch of 20-22 posterior lateral short setae and a line of minute, thin setae (Fig. 22). Last antennal segment on dorsal surface (Fig. 23) with 5-6 sensory spots; ventral surface with 5-6 spots (Fig. 24). Thorax. Pronotum with wide, irregular, nearly pentagonal, reddish brown, lateral scleromes and many long, slender setae not arranged in rows. 

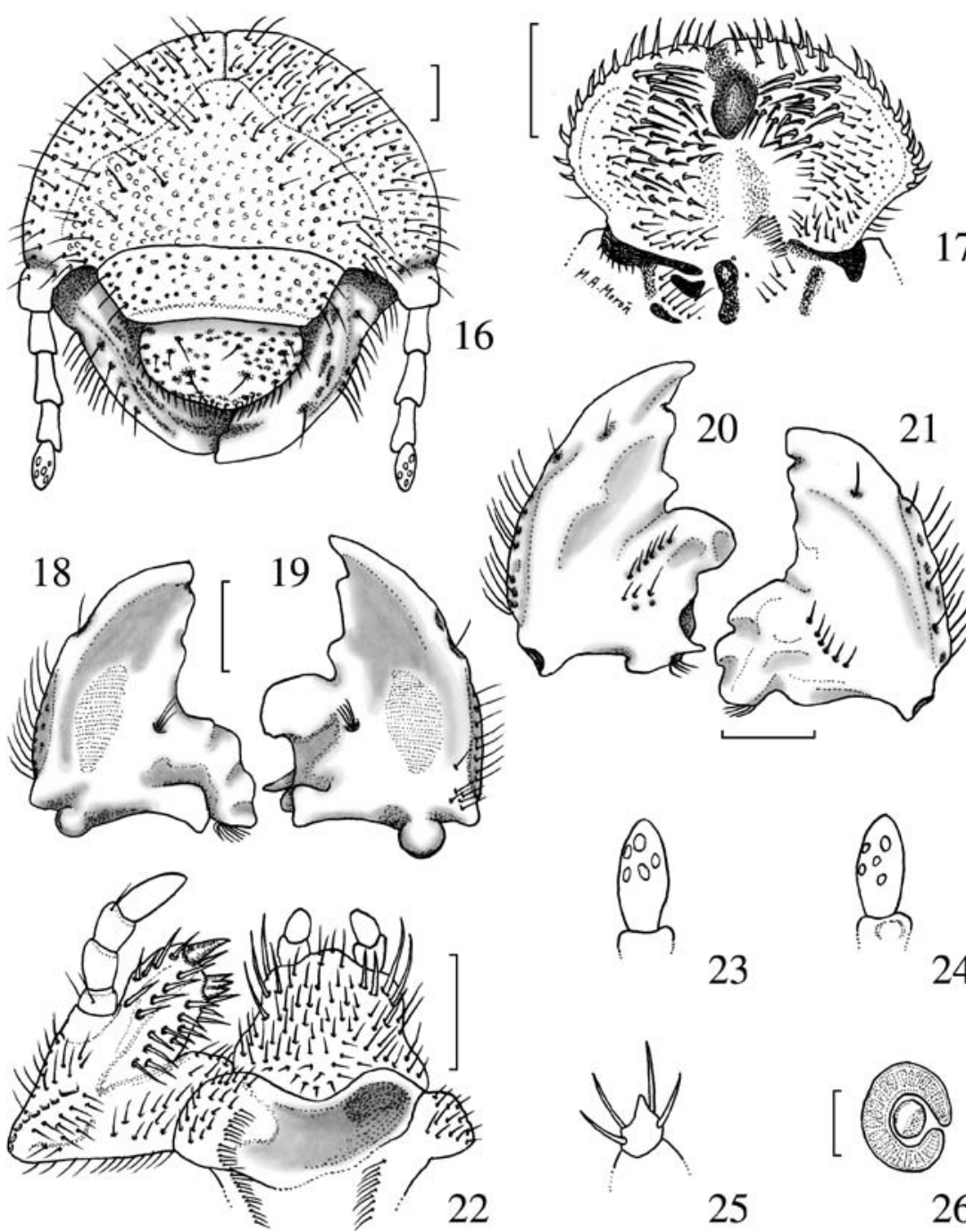

Figs. 16-26. Megasoma punctulatus, third instar. 16) Head, frontal view; 17) epipharynx; 18-19) mandibles, ventral view, 18) right and 19) left; 20-21) mandibles, dorsal view, 20) left and 21) right; 22) left maxilla and hypopharynx, dorsal view; 23-24) distal segment of antenna, 23) dorsal view and 24) ventral view; 25) left posterior tarsal claw, external view; 26) second right abdominal spiracle. Figs. $16-22$, bar $=1 \mathrm{~mm}$. Fig. 26, bar $=0.5 \mathrm{~mm}$.

Meso- and metanotum each with many long, slender setae not arranged in rows. Thoracic spiracles $0.69 \mathrm{~mm}$ long and $0.80 \mathrm{~mm}$ wide; lobes of respiratory plate nearly contiguous, directed posteriorly. Spiracular bulla rounded, convex, scarcely prominent. Tarsal claws (Fig. 25) similar on all legs, with acute apex, each bearing 2 internal, long, thick, basal setae and 2 external, long, thick, preapical setae. Abdomen. Dorsum of segment I with many long, slender setae not arranged in rows. Dorsa of segments II-VII (Fig. 27) each with mixture of long and short, spine-like setae, not arranged in rows, 


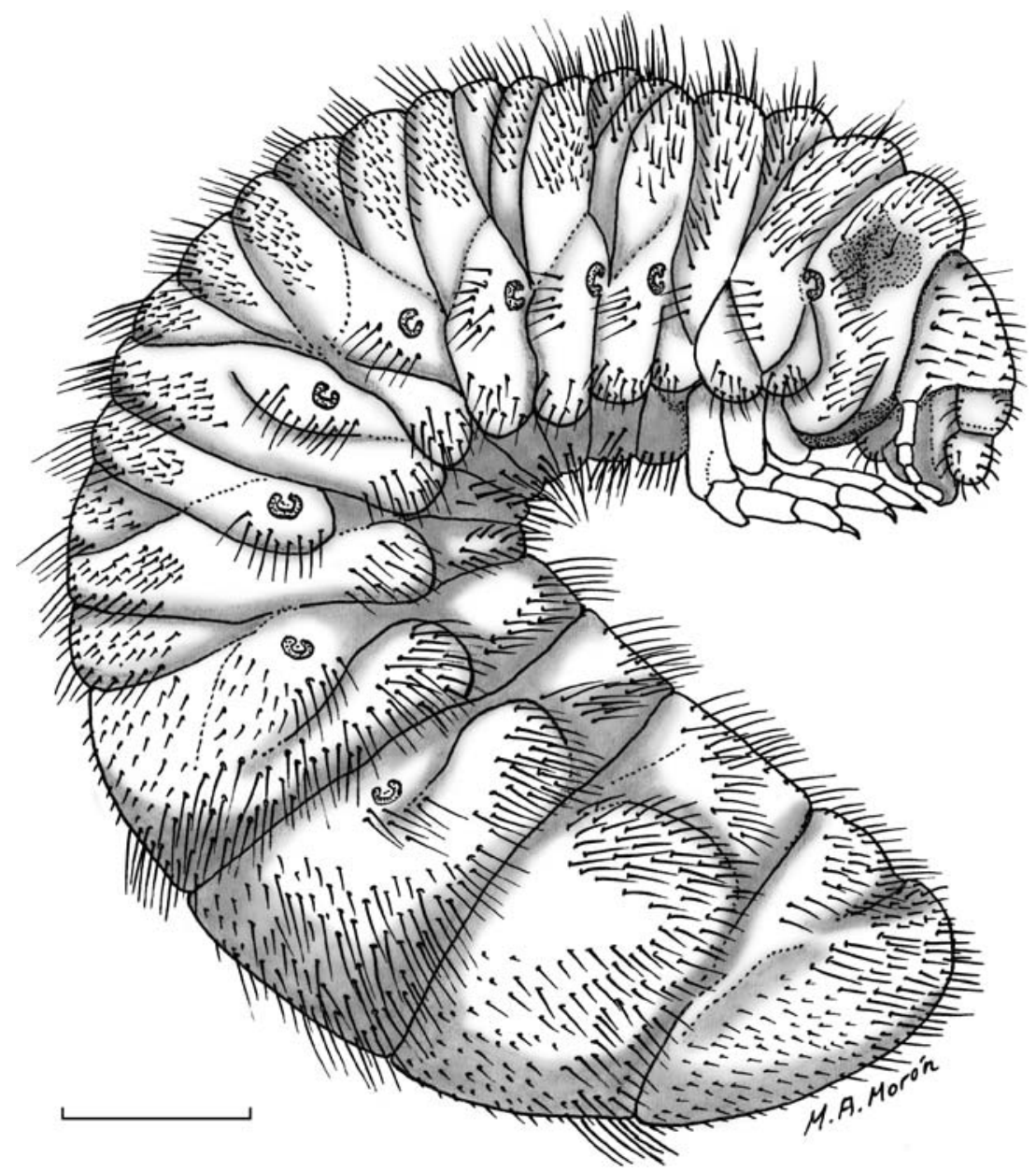

Fig. 27. Megasoma punctulatus, third instar, lateral view. Bar $=5 \mathrm{~mm}$. Setal pattern simplified.

with short setae predominant on anterior half of each annulet and long ones predominant on posterior half of each annulet. Dorsa of segments VIII-IX with scattered, spine-like setae and long setae mainly near sides and posterior border. Dorsum of segment $\mathrm{X}$ with numerous, short, spine-like setae on anterior $2 / 3$ and long setae on posterior third. Venter of abdominal segments I-IX each with median transverse tuft of long setae. Raster without pallidia and septula, with 28-30 long, slender setae on campus, teges formed by 42-46 slender setae; cuticle slightly rugose. Lower anal lip with 44-48 short, spine-like setae and 32-35 medium size, erect setae. Upper anal lip with 46-54 short, spine-like setae and 50-56 long, slender setae, mainly near sides. Spiracles of segments I-V progressively larger (0.60-0.80 mm long); spiracles of segments V-VIII progressively smaller (0.80-0.61 mm long); lobes of respiratory plate contiguous (Fig. 26), directed forward. Spiracular bulla convex, rounded, scarcely prominent; respiratory plate with 37-42 irregularly shaped holes across any diameter. Approximate dorsal body length $64 \mathrm{~mm}$.

Remarks. Shared characters of the larvae of $M$. punctulatus and $M$. thersites are: absence of anterior frontal setae, 2-3 dorsoepicranial setae, 40-46 epicranial setae, 45-50 setae on right chaetoparia, 7 maxillary stridulatory teeth, spine-like setae on 


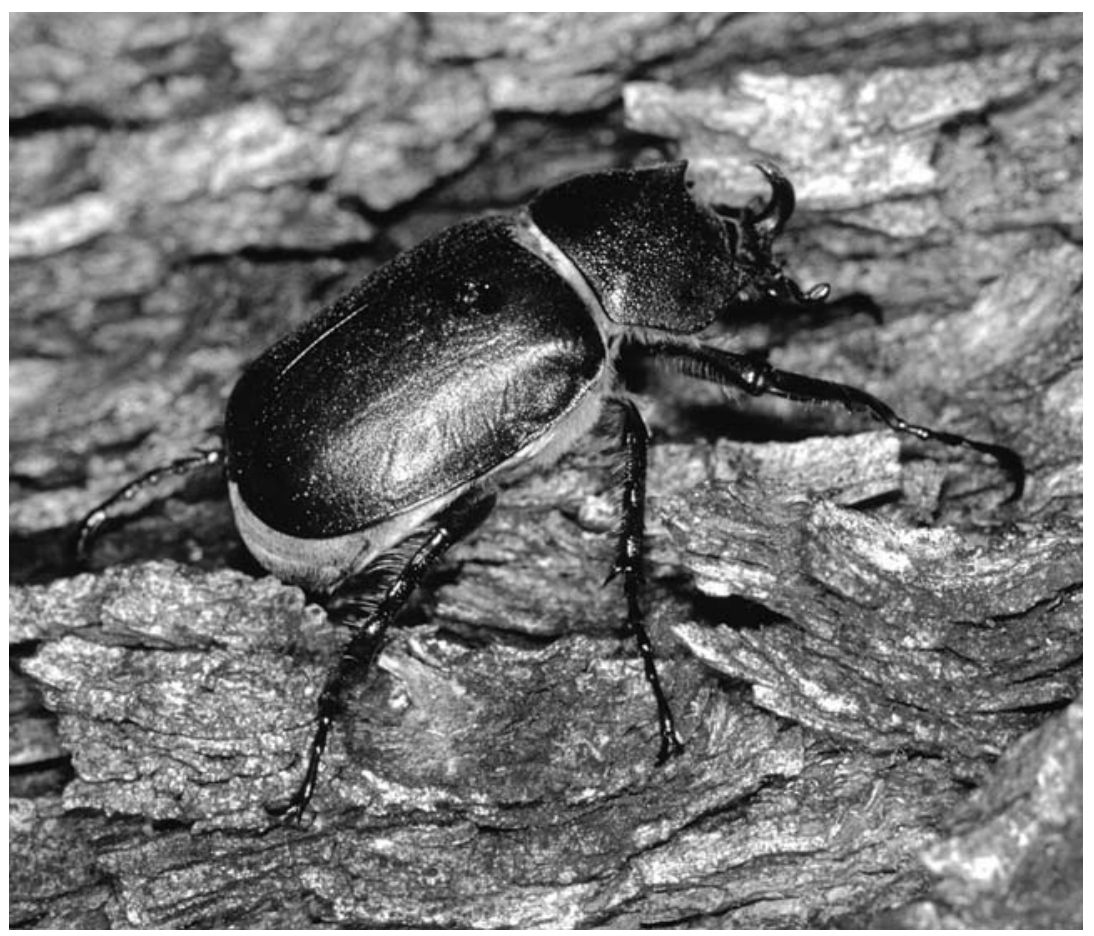

Fig. 28. Megasoma punctulatus on mesquite, Prosopis juliflora (Swartz). Photo by Barney Streit.

abdominal segment II, and bulla rounded, scarcely prominent. Similarities with the larvae of $M$. vogti consists of: 5-7 posterior frontal setae, 3-5 anterior angular frontal setae, 7 maxillary stridulatory teeth, 5-6 dorsal sensory spots on last antennal segment, 5-9 setae on acanthoparia, lobes of respiratory plates of spiracles contiguous, spine-like setae on abdominal segment II, and bulla rounded, scarcely prominent. The abundance of setae on the clypeus, labrum, and campus, absence of spine-like setae on the first abdominal segment, and an increase in the size of the abdominal spiracles toward segment $\mathrm{V}$, serves to distinguish the larvae of $M$. punctulatus.

Distribution and Habits. Adults of M. punctulatus (Fig. 28) have been collected in a limited number of localities of Arizona desert having a shrub cover of mesquite with occasional Quercus sp., Acacia spp., Mimosa sp., sycamore, hackberry, Condalia sp., Lycium sp., Agave and Opuntia species in the Santa Rita Range Reserve (Pima Co.), Patagonia, Rio Rico, and Duquesne (Santa Cruz Co.), and the Baboquivari Mts. of Arizona, between 1,300-1,350 m elevation. Males and females are attracted to lights but are also found on the trunks or branches of "catclaw" (Acacia greggi A. Gray, Mimosaceae). Adults are active during July and August (Cartwright 1952; Hardy 1972).

\section{Megasoma thersites LeConte, 3rd instar}

(Figs. 29-42)

Description based on one third instar larva collected in México: Baja California Sur, 11 mi N Cabo San Lucas, 26-IV-1985, from soil dug for post hole, R.L. Westcott (UNSM). 

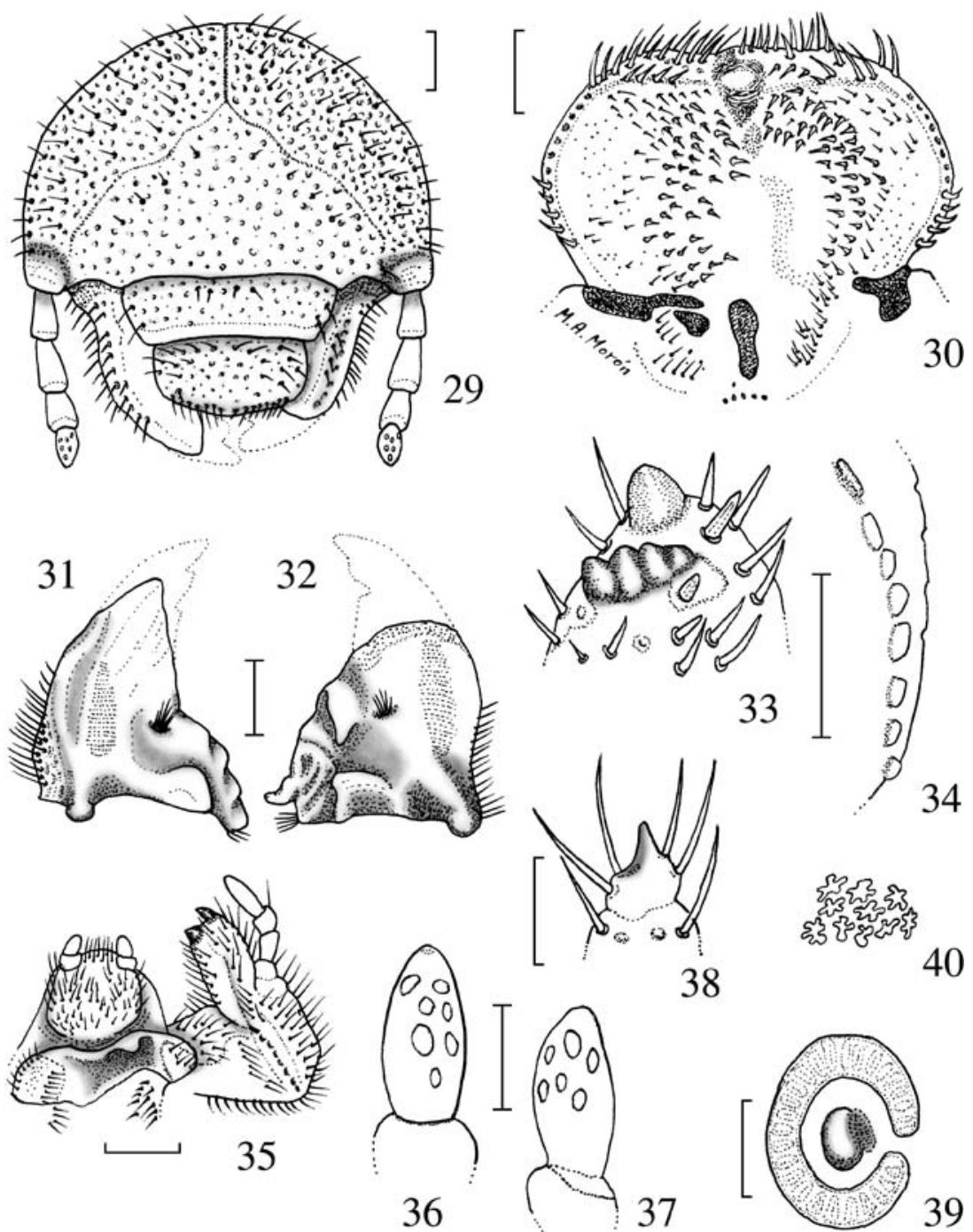

Figs. 29-40. Megasoma thersites, third instar. 29) Head, frontal view; 30) epipharynx; 31-32) mandibles, ventral view, 31) right and 32) left; 33) distal part of right maxillary mala; 34) detail of maxillary stridulatory area; 35) right maxilla and hypopharynx, dorsal view; 36-37) distal segment of antenna, 36) dorsal view and 37) ventral view; 38) left posterior tarsal claw, external view; 39) second right abdominal spiracle; 40) microstructure of respiratory plate (500×). Figs. 29-32, 35, bar $=1 \mathrm{~mm}$. Figs. 33-34, 36-39, bar $=0.5 \mathrm{~mm}$.

Description. Head. Maximum width of head capsule $7.4 \mathrm{~mm}$. Surface of cranium (Fig. 29) dark brown, punctate, punctures large, deep. Frons moderately punctate, each side with 3 posterior frontal setae, anterior frontal setae lacking, 1 exterior frontal setae, and 6 anterior angle frontal setae. Remaining cranial surface with 2 dorsoepicranial, short setae, 46 epicranial setae, and 3 


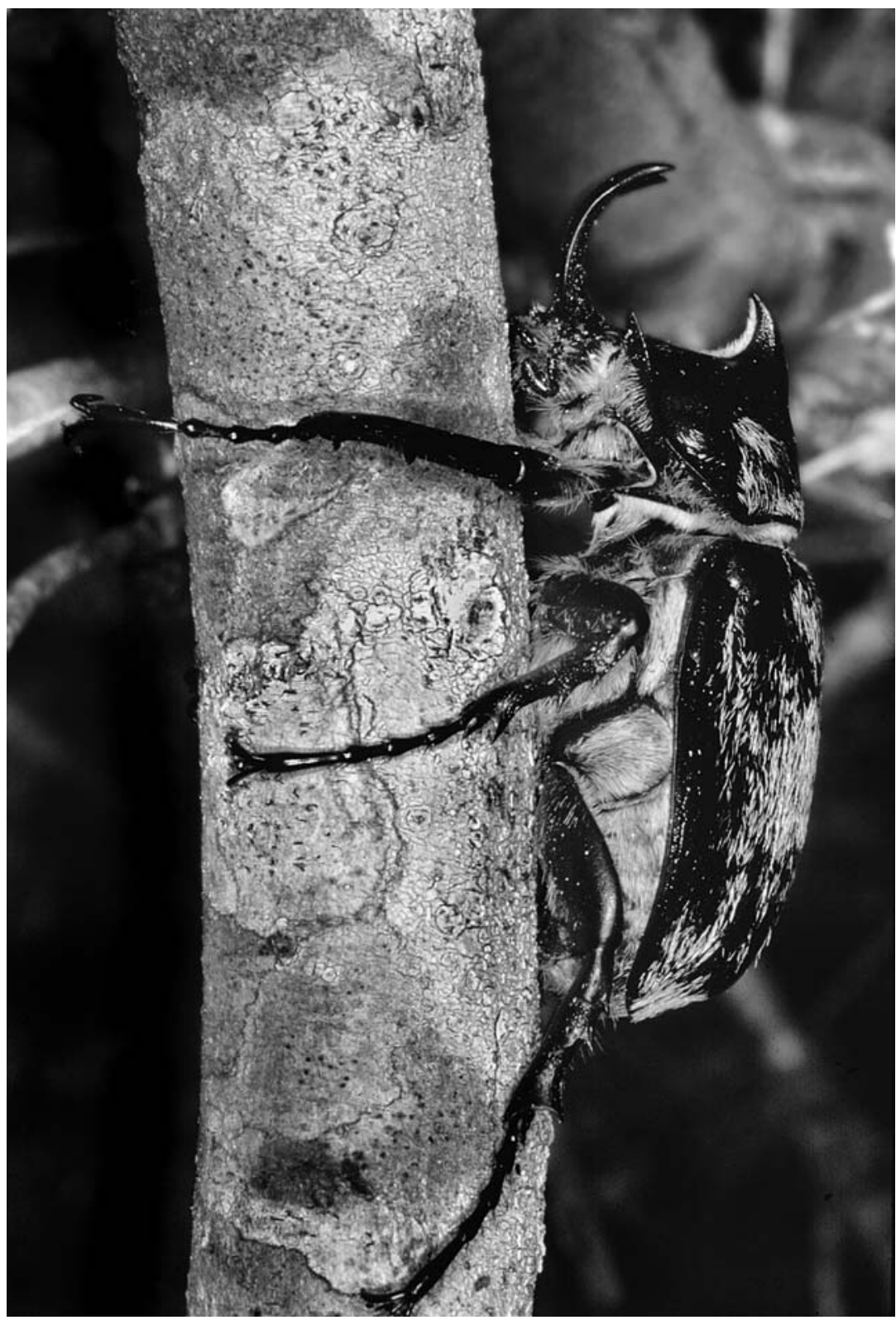

Fig. 41. Megasoma thersites on palo verde, Cercidium microphyllum Rose \& I. M. Johnst. Photo by Barney Streit. 


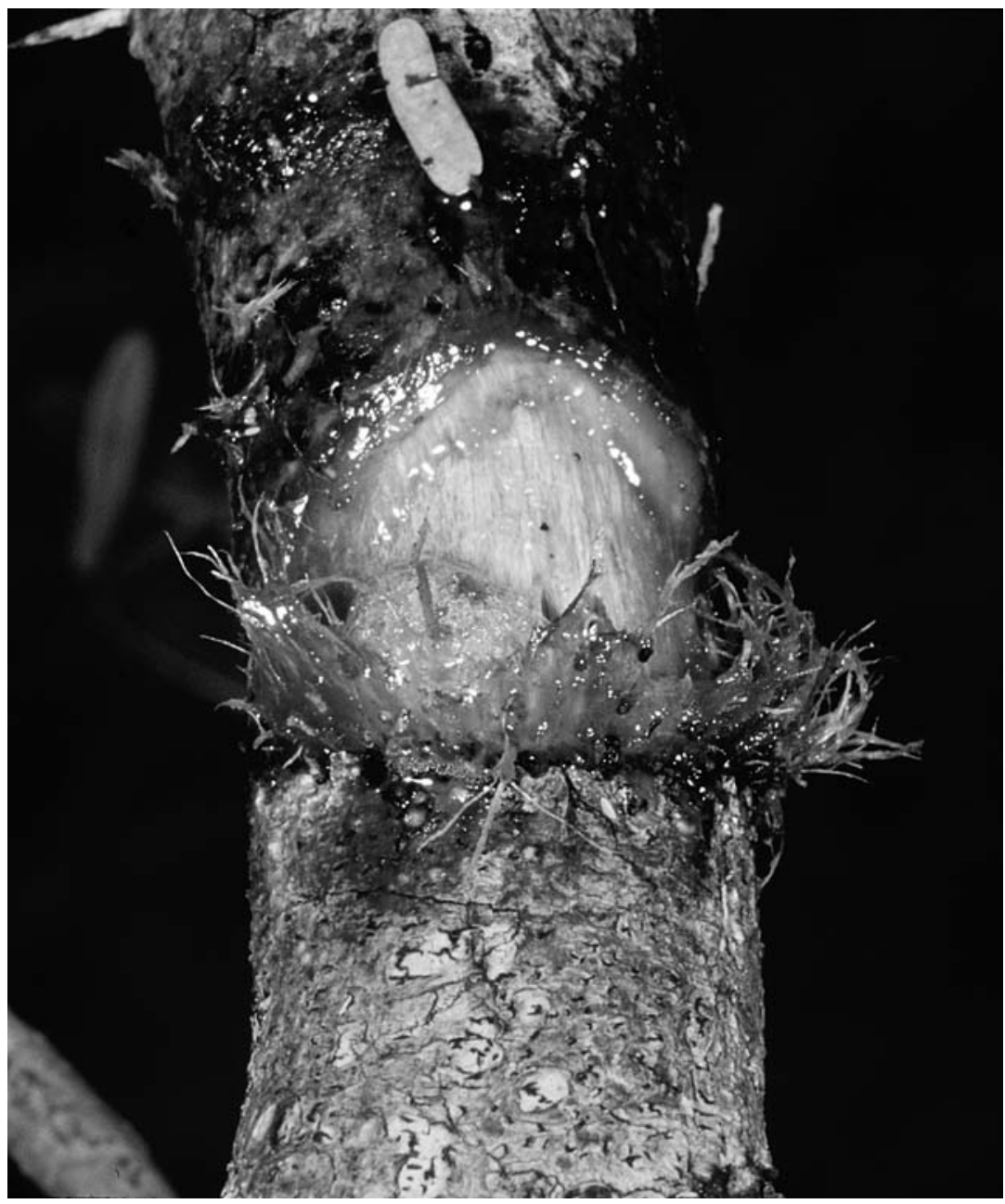

Fig. 42. "Gumming wound" made by adult Megasoma thersites on palo verde tree. Photo by Barney Streit.

paraocellar setae on each side. Clypeus trapezoidal, with 2 lateral setae on each side and 4 posterior clypeal setae. Labrum slightly asymmetrical, subrectangular, with row of 15 anterior labral setae, widely interrupted at middle, 7 posterior setae, central setae absent, and 5-6 lateral setae. Ocelli not apparent. Epipharynx (Fig. 30) with fused zygum and epizygum forming weakly raised, subconical, sclerotized tubercle on haptomerum; heli and plegmatia absent; right chaetoparia with 50 spine-like setae and 45 small setae and sensillae toward gymnoparia; left chaetoparia with 35 spine-like setae and 40 small setae and sensillae; acroparia with 9 straight, long, thick setae toward right side and 10 straight, long, thick setae toward left side; right acanthoparia with 12 short, curved, spine-like setae or insertion pits; left acanthoparia with 13 short, curved, spine-like setae or insertion pits; pedium wide and epitorma not defined; dexiotorma long, sinuate, with rounded inner side; laeotorma short, with rounded inner side and subquadrate pternotorma; dexiophoba sparse, formed by 11 setae; laeophoba between haptolachus 
and inner side of laeotorma formed by 32 setae; sclerotized plate of right nesium large, subpyriform; sense cone of left nesium represented by large, wide, longitudinal, well-sclerotized plate with rounded ends and row of 5 sensillae near base; crepis not defined. Scissorial area of right mandible (Fig. 31) widely abraded, without evidence of teeth or notches; molar area with 3 lobes, calx prominent, brustia sparse. Scissorial area of left mandible (Fig. 32) deeply abraded, without evidence of teeth or notches; molar area with 2 wide lobes, brustia sparse, long acia with rounded apex. Stridulatory area of each mandible well-marked by 22-24 fine striae. Mala (Fig. 33 ) with apical uncus of galea well-developed and 3 conical unci fused at their bases at apex of lacinia ( 2 of these abraded); maxillary stridulatory area (Fig. 34) with 7 small, subtrapezoidal, rounded teeth and wide, truncate anterior process. Labium (Fig. 35) with numerous long, strong setae located on sides and short, spine-like setae at middle and proximal border; hypopharynx with right anterior lateral process of hypopharyngeal sclerome strongly developed, raised and curved, heavily sclerotized; left hypopharyngeal lateral lobe with patch of 20 posterolateral short setae and a line of 9 minute, thin setae. Last antennal segment on dorsal surface (Fig. 36) with 7 sensory spots; ventral surface with 6 spots (Fig. 37). Thorax. Pronotum with wide, irregular, reddish brown, lateral scleromes and 140 long, slender setae near anterior border and 44 medium sized, slender setae near posterior border, setae not arranged in definite rows. Mesonotum with 3 transverse groups of 20-90 long, slender setae and 4 groups of 18-48 medium sized, slender setae; metanotum with 4 transverse groups of 35-80 long, slender setae, 3 groups of 10-22 medium sized, slender setae and 1 group of 20 short, spine-like setae, setae not arranged in rows. Thoracic spiracles $0.66 \mathrm{~mm}$ long and $0.81 \mathrm{~mm}$ wide; lobes of respiratory plate nearly contiguous, directed posteriorly. Spiracular bulla rounded, convex, irregular, scarcely prominent. Tarsal claws (Fig. 38) similar on all legs, with acute apex, each bearing 2 internal, long, thick, basal setae and 2 external, long, thick, preapical setae. Abdomen. Dorsum of segment I with 2 rows of 30-34 short, spine-like setae, 4 rows of 20-46 medium sized, slender setae, and 2 rows of 36-38 long, slender setae, and more than 120 long setae on each side. Dorsa of segments II-VI each with 85-100 long setae mainly on sides and 90-120 spine-like, short setae mixed with long setae; at middle third these setae form more or less regular row of 20-24 long setae. Dorsum of segment VII with more than 200 long, slender setae, more than 100 short, spine-like setae on each side, and transverse, anterior row of 36 slender, long setae. Dorsum of segment VIII with 1 row of 26 long, slender setae, more than 100 short, spine-like setae, and 80 long setae on each side. Dorsum of segment IX with 2 rows of 20-30 long, slender setae and 50 long slender setae and more than 80 short, spine-like setae on each side. Dorsum of segment X with approximately 200 short spine-like setae and 40 long, slender setae on each side. Venter of abdominal segments I-II each with 5 rows of 40-45 long, slender setae and 2 rows of 30-35 medium sized, slender setae; venter of segments III-V each with 1 row of 20 long, slender setae, and 2 rows of 25-30 medium sized, slender setae; venter of segments VI-VIII each with 80 long and medium sized, slender setae on each side; venter of segment IX with 70 long and medium sized, slender setae on each side. Raster without pallidia and septula, with 20 long, slender setae on campus, teges formed by 10 medium sized, slender setae; cuticle slightly rugose. Barbula formed by 20-25 long, slender setae. Lower anal lip with 140 long and medium sized mixed, slender setae. Upper anal lip with more than 100 short, spine-like setae and long, slender setae mixed, mainly towards sides. Spiracles of segments I-VIII progressively shorter $(0.7-0.6 \mathrm{~mm}$ long; $1.0-0.8 \mathrm{~mm}$ wide); lobes of respiratory plate separated by distance less than $1 / 3$ diameter of convexity of bulla (Fig. 39), directed anteriorly. Spiracular bulla convex, rounded, weakly prominent; respiratory plate with about 28 irregularly shaped holes (Fig. 40) across any diameter. Approximate dorsal body length $85 \mathrm{~mm}$.

Second-instar Larva. Based on one third instar larva reared from egg laid by female collected in México: Baja California Sur, San José del Cabo, 2-X-1999, 580 m, fixed 5IV-2000, G. Nogueira (IEXA).

Description. Similar to third-instar larva except as follows: maximum width of head capsule $5.0 \mathrm{~mm}$. Right chaetoparia with 38 spine-like setae and 34 small setae and sensillae; left chaetoparia with 24 spine-like setae and 32 small setae and sensillae. Scissorial area of both mandibles with 3 teeth clearly separated by notches. Prothoracic spiracles $0.23 \mathrm{~mm}$ long, $0.35 \mathrm{~mm}$ wide. Abdominal spiracles progressively smaller (0.16-0.13 mm long, $0.34-0.29 \mathrm{~mm}$ wide). Approximate dorsal body length $26 \mathrm{~mm}$. 
First-instar Larva. Based on nine first-instar larvae reared from eggs laid by female collected in México: Baja California Sur, San José del Cabo, 2-X-1999, 580 m, fixed 15XII-1999, G. Nogueira (IEXA).

Description. Similar to second-instar larva except as follows: maximum width of head capsule 2.7-3.0 mm. Sclerotized plates on sides of pronotum absent. Eclosion spine on each side of metanotum small, conical, surrounded by 3 short, spine-like setae. Thoracic spiracles $0.13 \mathrm{~mm}$ wide, $0.04 \mathrm{~mm}$ long. Abdominal spiracles similar in size, 0.14 $\mathrm{mm}$ wide, $0.02 \mathrm{~mm}$ long, without bulla. Approximate dorsal body length $4.5-6.0 \mathrm{~mm}$.

Remarks. Larvae of $M$. thersites are similar to those of $M$. vogti and M. punctulatus but may be distinguished by 3 postfrontal setae on each side, 6 anterior angle frontal setae, 7 setae near the posterior border of the labrum, pternotorma subquadrate, 7 dorsal sensory spots on the last antennal segment, acanthoparia with 12-13 setae, and lobes of the respiratory plate of the spiracles narrowly separated.

Distribution and Habits. Adults of $M$. thersites have been collected in many localities in the state of Baja California Sur, México such as Todos Santos, La Paz, Cabo San Lucas, and San José del Cabo at elevations from sea level to 600 meters (Hardy 1972). Males and females are attracted to lights during September and October, but they are also commonly found in the soil or on branches of "palo verde," (Cercidium peninsulare Rose, Caesalpinaceae) where adults feed on the cambium (Fig. 41) by "gumming" away the bark layer (Fig. 42).

\section{Megasoma vogti Cartwright, 3rd instar}

(Figs. 43-54)

Description based on remnants of one third instar larvae reared from egg laid by female collected in U.S.A., Texas, Live Oak Co, X-1989, D. W. Sundberg (UNSM).

Description. Head. Maximum width of head capsule $8.4 \mathrm{~mm}$. Surface of cranium dark brown, rugopunctate, punctures large, deep. Frons uniformly punctate (Fig. 43), each side with 5-7 posterior frontal setae, 6-7 anterior frontal setae, 7-9 exterior frontal setae, and 4-5 anterior angle frontal setae; remaining cranial surface with 1 dorsoepicranial, short seta, 30-36 epicranial setae, and 2-3 paraocellar setae on each side. Clypeus trapezoidal, with 2 lateral setae on each side, 2 anterior setae, and no posterior clypeal setae. Labrum slightly asymmetrical, subovate, rounded at sides, with row of 21 anterior labral setae, not interrupted at middle, no posterior setae, 4 central setae, and 2 lateral setae on each side. Ocelli not apparent. Epipharynx (Fig. 44) with fused zygum and epizygum forming poorly raised, longitudinal, sclerotized tubercle on haptomerum; heli and plegmatia absent; right chaetoparia with mixture of 70 spine-like setae and 15 sensillae; left chaetoparia with mixture of less than 80 spine-like setae and sensillae; acroparia with 10 straight, long, thick setae on right side and 16 straight, long, thick setae on left side; right acanthoparia with 9 short, curved, spine-like setae; left acanthoparia with 5 short, curved, spine-like setae; pedium wide, epitorma poorly defined; dexiotorma wide, with large, truncate, inner side; laeotorma short, with narrowed inner side and widely rounded pternotorma; dexiophoba not apparent; laeophoba between haptolachus and inner side of laeotorma formed by 3 setae; sclerotized plate on right nesium elongate; sense cone on left nesium represented by large, longitudinal, well-sclerotized plate with rounded anterior side and truncate posterior side; crepis not defined. Scissorial area of right mandible (Figs. 46, 49) slightly abraded, with 3 scissorial teeth clearly separated by notches, and 1 basal, rounded tooth; molar area with 3 poorly defined lobes; calx prominent, brustia sparse. Scissorial area of left mandible (Figs. 47-48) slightly abraded, with 3 scissorial teeth clearly separated by notches, and 1 basal, wide, rounded tooth; molar area with 2 wide lobes, brustia sparse and acia short with rounded apex. Stridulatory area of each mandible well-marked by about 23-25 fine striae. Mala (Fig. 45) with apical uncus of galea well-developed, and 3 conical unci fused at their bases at apex of lacinia; maxillary stridulatory area (Fig. 50) with 7 small, truncate or round teeth, and wide, truncate anterior process. Labium (Fig. 45) with numerous long, strong setae located on sides and short, spine-like setae at middle and proximal border; hypopharynx with right anterior lateral process of hypopharyngeal sclerome strongly developed, raised and curved, heavily sclerotized; left hypopharyngeal lateral lobe with patch of 16 posterolateral, short setae and 1 line of 12 , slender 

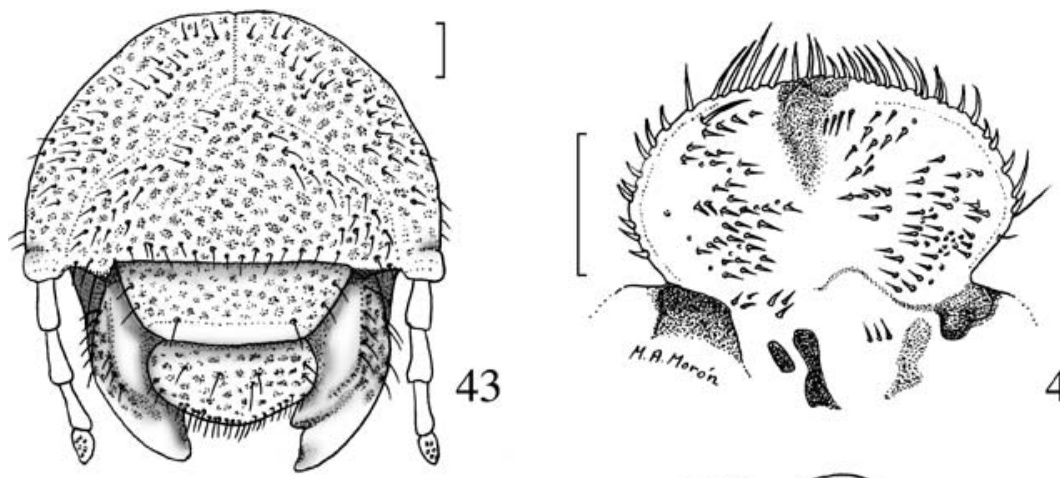

44

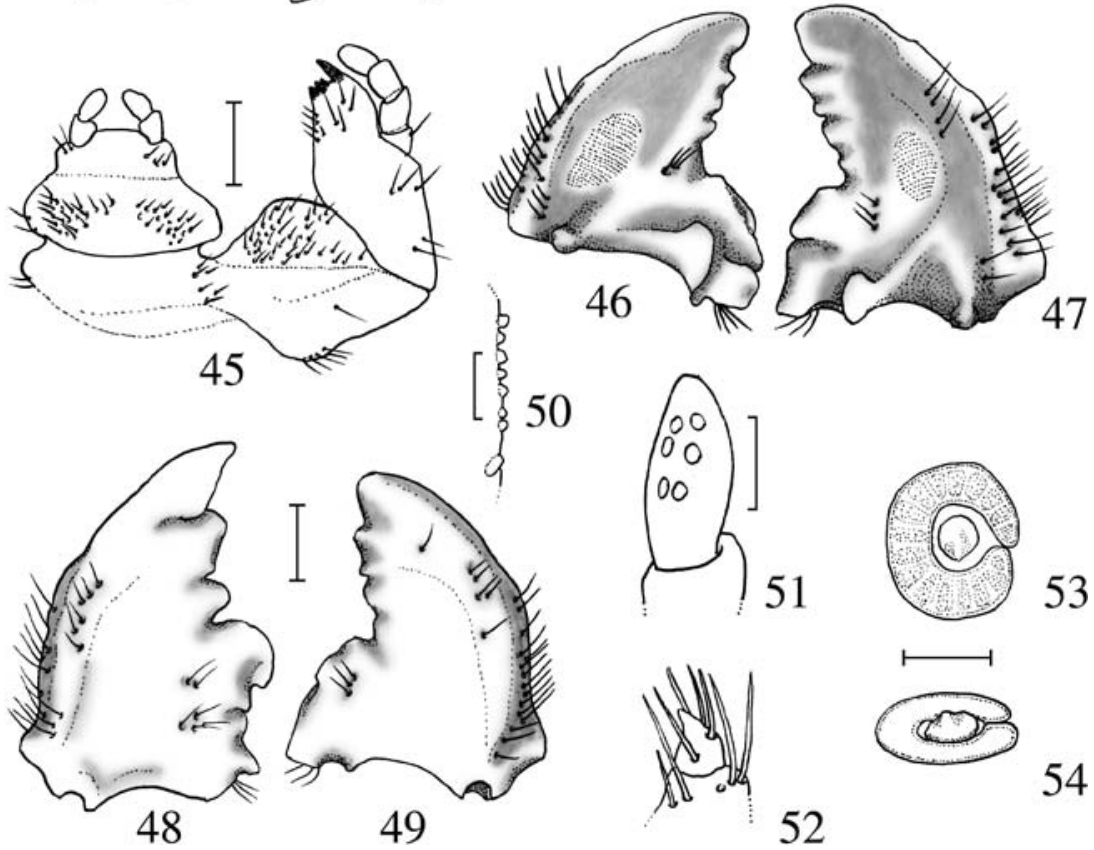

Figs. 43-54. Megasoma vogti, third instar. 43) Head, frontal view; 44) epipharynx; 45) left maxilla and labium, ventral view; 46-47) mandibles, ventral view, 46) right and 47) left; 48-49) mandibles, dorsal view, 48) left and 49) right; 50) detail of maxillary stridulatory area; 51) distal segment of antenna, dorsal view; 52) left posterior tarsal claw, external view; 53-54) second right abdominal spiracle, 53) lateral view and 54) left ventrolateral view. Figs. 43-49, bar $=1 \mathrm{~mm}$. Figs. 50-54, bar $=0.5 \mathrm{~mm}$.

setae. Last antennal segment on dorsal surface (Fig. 51) with 6 sensory spots; ventral surface with 6 spots. Thorax. Pronotum with wide, irregular, reddish brown, lateral scleromes and about 90 long, slender setae near anterior border and 40 medium sized, slender setae near posterior border, setae not arranged in definite rows. Mesonotum with 3 transverse groups of 25-70 long, slender setae and 4 groups of 15-40 medium sized, slender setae; metanotum with 4 transverse groups of 30-70 long, slender setae, 3 groups of 10-12 medium sized, slender setae, and 1 group of 23 short, spine-like setae, setae not arranged in rows. Thoracic spiracles $0.60 \mathrm{~mm}$ long and $0.78 \mathrm{~mm}$ wide; lobes of 
respiratory plate contiguous, directed posteriorly. Spiracular bulla rounded, convex, irregular, scarcely prominent. Tarsal claws (Fig. 52) similar on all legs, with acute apex, each bearing 2 internal, long, thick, basal setae and 2 external, long, thick preapical setae. Abdomen. Dorsum of segment I with 2 rows of 26-30 short, spine-like setae, 4 rows of 20-34 medium sized, slender setae, and 2 rows of 30-34 long, slender setae, and more than 100 long setae on each side. Dorsa of segments II-VI each with 75-90 long setae mainly on sides and 70-100 spine-like, short setae mixed with long setae; on middle third these setae form more or less regular row of 20-22 long setae. Dorsum of segment VII with more than 120 long, slender setae, more than 80 short, spine-like setae on each side, and transverse, anterior row of 26 slender, long setae. Dorsum of segment VIII with 1 row of 24 long, slender setae, more than 100 short, spine-like setae, and 70 long setae on each side. Dorsum of segment IX with 2 rows of 18-26 long, slender setae, and 40 long, slender setae and more than 90 short, spine-like setae on each side. Dorsum of segment X with approximately 120 short, spine-like setae and 50 long, slender setae on each side. Venter of abdominal segments I-II each with 5 rows of 35-40 long, slender setae and 2 rows of 28-32 medium sized, slender setae; venter of segments III-V each with 1 row of 22 long, slender setae and 2 rows of 25-30 medium sized, slender setae; venter of segments VI-VIII each with 86 long and medium sized, slender setae on each side; venter of segment IX with 70 long and medium sized, slender setae on each side. Raster without pallidia and septula, with 18 long, slender setae on campus, teges formed by 12 medium sized, slender setae; cuticle slightly rugose. Barbula formed by $25-28$ long, slender setae. Lower anal lip with about 100 mixed long and medium size, slender setae. Upper anal lip with more than 80 mixed short, spine-like setae and long, slender setae, mainly on sides. Spiracles of segments I-VIII progressively shorter $(0.7-0.6 \mathrm{~mm}$ long; $1.0-0.8 \mathrm{~mm}$ wide); lobes of respiratory plate contiguous (Fig. 53), directed anteriorly. Spiracular bulla convex, irregularly rounded, weakly prominent (Fig. 54); respiratory plate with about 30 irregularly shaped holes across any diameter. Approximate dorsal body length not measurable.

Remarks. Larvae of $M$. vogti are similar to those of $M$. punctulatus by the presence of 3-5 anterior angle frontal setae, 7 maxillary stridulatory teeth, 5-6 dorsal sensory spots on the last antennal segment, acanthoparia with 5-9 setae, dorsum of abdominal segment II with spine-like setae, lobes of respiratory plates of spiracles contiguous, and bulla rounded and scarcely prominent. However, the 6-7 anterofrontal setae, absence of posterior setae on the labrum, 70 setae on the right chaetoparia, dexiotorma widened with the inner side truncate, dorsum of abdominal segment I with spine-like setae, 18 setae on the campus, and abdominal spiracles progressively smaller towards segment VIII will serve to separate $M$. vogti.

Distribution and Habits. Adults of $M$. vogti have been recorded in a small number of localities in Hidalgo Co., Jim Wells Co., and Live Oak Co., Texas, U.S.A., and Salinas Victoria, state of Nuevo León, and Buenavista, state of Tamaulipas, México, between 100 to 400 meters in elevation (Cartwright 1963, 1970; Hardy 1972). Vegetation in these areas is comprised of mesquite, thorn shrubs, cacti, and occasional small trees. Males and females were collected from July to October either being attracted to lights, found on the soil surface, or on branches of "mezquite" (Prosopis juliflora [Swartz] Mimosaceae).

\section{Megasoma cedrosa Hardy, 3rd instar}

(Figs. 55-66)

Description based on two third instar larvae reared from eggs laid by females collected in México: Baja California, Hwy 1, $1 \mathrm{~km} \mathrm{~N}$ Rancho El Progreso, vicinity Hwy marker 115, 21-VIII-1998, R. A. Cunningham and J. D. Bever collectors; eggs laid 22-26-VIII-1998; larvae fixed 22-VII-1999 (UNSM, IEXA).

Description. Head. Maximum width of head capsule $7.3 \mathrm{~mm}$. Surface of cranium dark brown, densely punctate, punctures deep. Frons irregularly punctate (Fig. 55), each side with 3-4 posterior frontal setae, 10-11 anterior frontal setae, 2-4 exterior frontal setae, and 3 anterior angle frontal setae; remaining cranial surface with 1 row of 7-10 setae near dorsoepicranial suture, 10-16 epicranial setae, and no paraocellar setae on each side. Clypeus trapezoidal, with 2 lateral setae on 

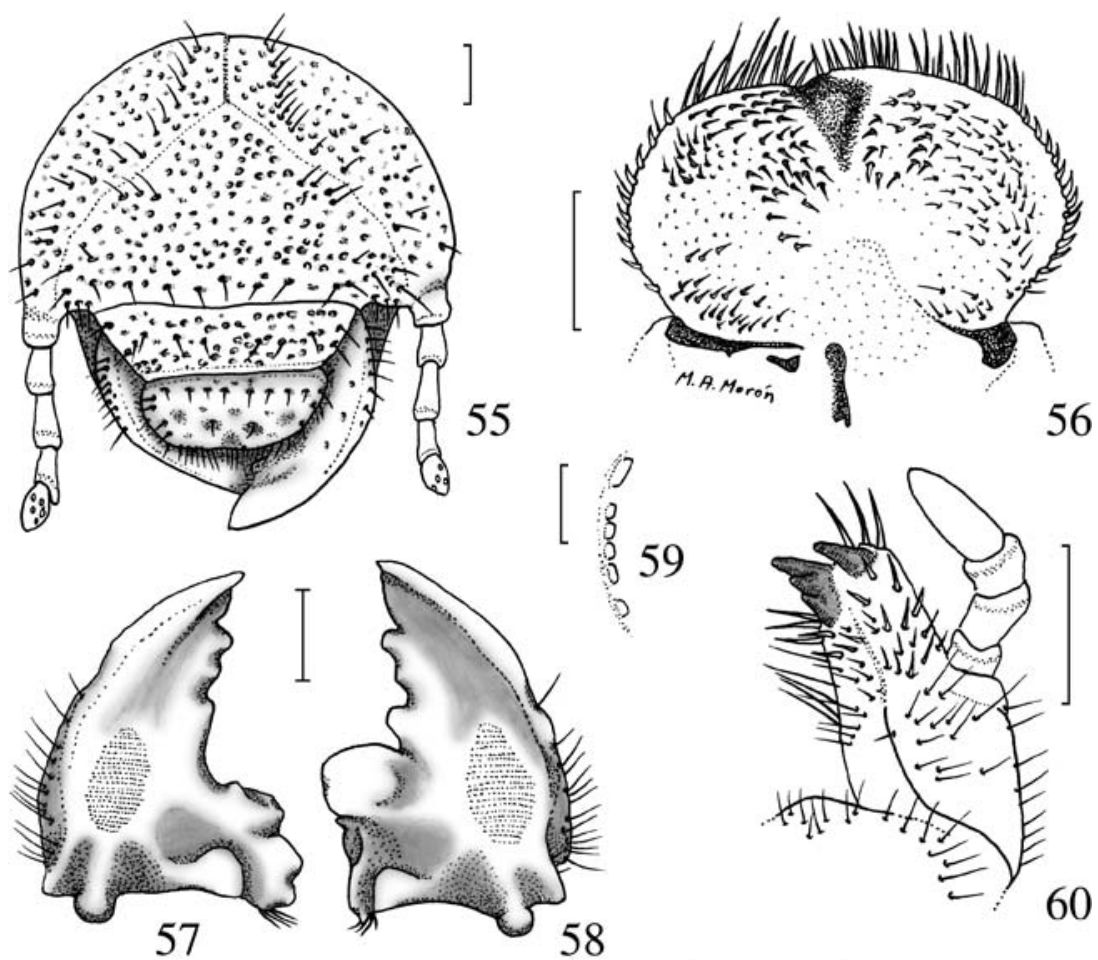

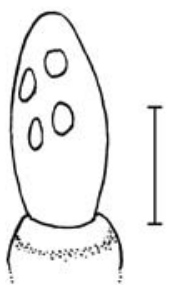

61

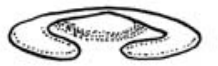

62
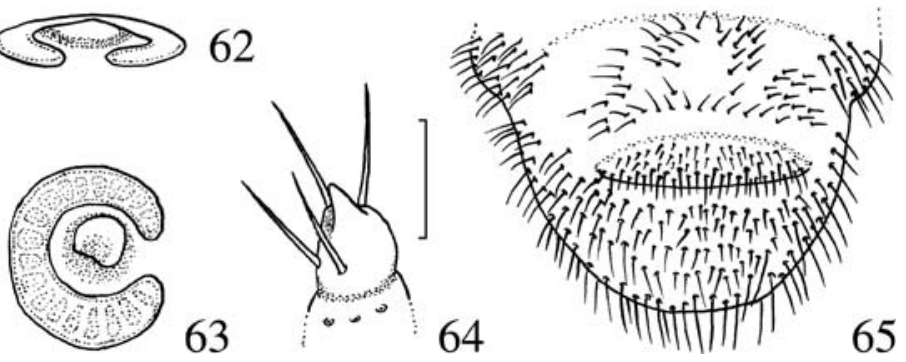

Figs. 55-65. Megasoma cedrosa, third instar. 55) Head, frontal view; 56) epipharynx; 57-58) mandibles, ventral view, 57) right and 58) left; 59) detail of maxillary stridulatory area; 60) left maxilla, ventral view; 61) distal segment of antenna, dorsal view; 62-63) second right abdominal spiracle, 62) anterolateral view and 63) lateral view; 64) left posterior tarsal claw, external view; 65) last abdominal segment, ventral view with raster. Figs. 55-58, 60, 65, bar $=1 \mathrm{~mm}$. Figs. 59, $61-64$, bar $=0.5 \mathrm{~mm}$. Fig. 65 , bar $=5 \mathrm{~mm}$.

each side, 5-6 discal setae and no posterior clypeal setae. Labrum slightly asymmetrical, rounded at sides, with row of 20-24 anterior labral setae, vaguely interrupted at middle, 8-10 posterior setae, 2 central setae, and 4 lateral setae on each side. Ocelli not apparent. Epipharynx (Fig. 56) with fused zygum and epizygum forming moderately raised, longitudinal, sclerotized tubercle on haptomerum; heli and plegmatia absent; right chaetoparia with mixture of 64-70 spine-like setae and 24-30 sensillae; left chaetoparia with mixture of 90 spine-like setae and 5-8 sensillae; acroparia with 14- 


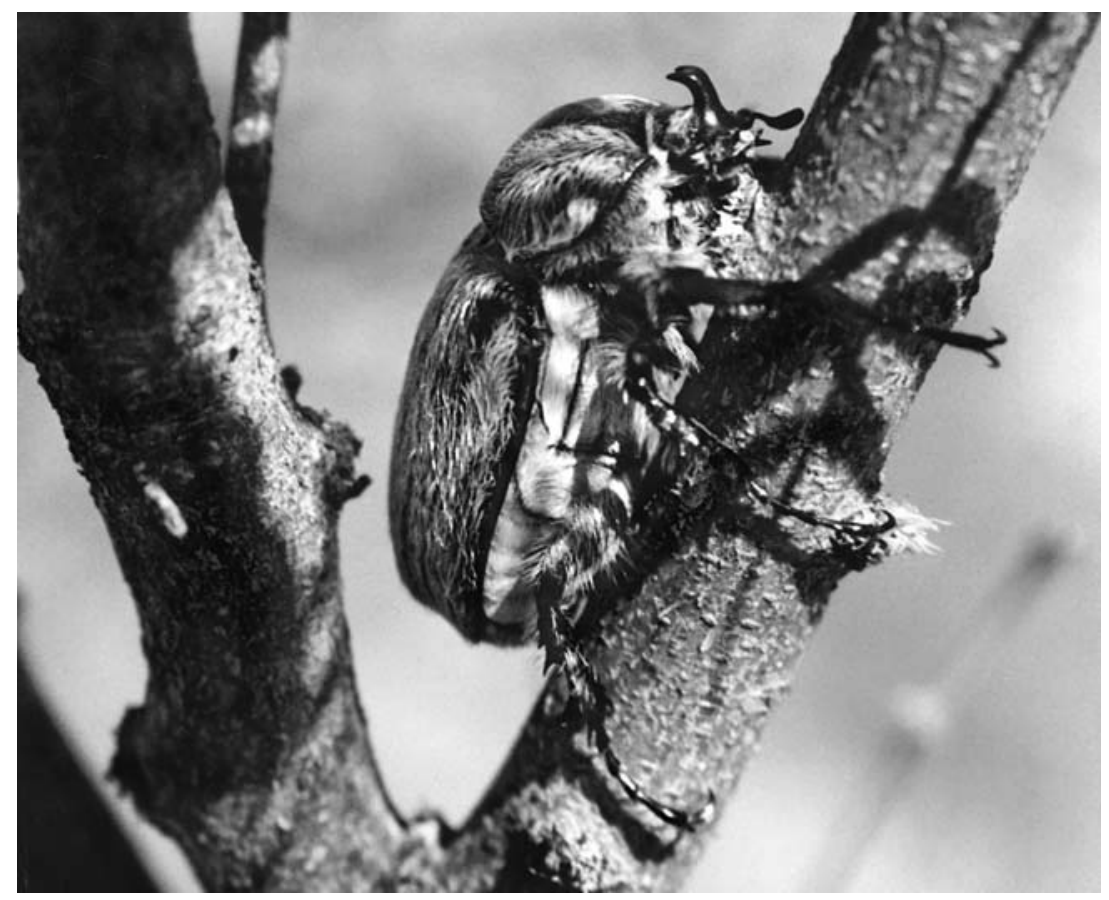

Fig. 66. Megasoma cedrosa on branch of Acacia sp. Photo by David Russell.

16 straight, medium sized, thick setae on right side and 11-12 straight, short, thick setae on left side; right acanthoparia with 10 short, curved, spine-like setae; left acanthoparia with 13-14 short, curved, spine-like setae; pedium wide, epitorma poorly defined; dexiotorma narrowed toward acute inner side; laeotorma short, with narrowed inner side and widely rounded pternotorma; dexiophoba not apparent; laeophoba between haptolachus and inner side of laeotorma not apparent; sclerotized plate on right nesium irregularly shaped; sense cone on left nesium represented by large, longitudinal, well-sclerotized plate with rounded anterior side and sinuated posterior side; crepis not defined. Scissorial area of right mandible (Fig. 57) slightly abraded, with 2 scissorial teeth clearly separated by notches, 2 vaguely defined, rounded teeth, and 1 basal, rounded tooth; molar area with 3 poorly defined lobes, calx prominent, brustia sparse. Scissorial area of left mandible (Fig. 58) slightly abraded, with 2 scissorial teeth clearly separated by notches, 1 scarcely defined tooth, and 1 basal, wide, rounded tooth; molar area with 2 wide lobes, brustia sparse and acia short with rounded apex. Stridulatory area of each mandible well-marked by about 22-26 fine striae. Mala (Fig. 60) with apical uncus of galea well-developed and 3 conical unci fused at their bases at apex of lacinia; maxillary stridulatory area (Fig. 59) with 5 small, rounded teeth, and wide, truncate anterior process. Labium with numerous, long, strong setae located on sides and short, spine-like setae at middle and proximal border; hypopharynx with right anterior lateral process of hypopharyngeal sclerome strongly developed, raised and curved, heavily sclerotized; left hypopharyngeal lateral lobe with patch of 22 posterolateral, short setae and 1 line of 10 slender setae. Last antennal segment on dorsal surface (Fig. 61) with 4 sensory spots; ventral surface with 5 spots. Thorax. Pronotum with wide, irregularly shaped, yellowish, lateral scleromes and about 80 long, slender setae near anterior border, setae not arranged in definite rows; spine-like, short setae absent. Mesonotum with 3 transverse groups of 32-64 long, slender setae; spine-like, short setae absent. Metanotum with 4 transverse groups of 38-72 long, slender setae, setae not arranged in rows. Thoracic spiracles 0.65 $\mathrm{mm}$ long and $0.85 \mathrm{~mm}$ wide; lobes of respiratory plate separated by distance slightly shorter than dorsoventral diameter of bulla, directed posteriorly. Spiracular bulla rounded, convex, irregular, 
scarcely prominent. Tarsal claws (Fig. 64) similar on all legs, with acute apex, each bearing 2 internal, long, thick, basal setae and 2 external, long, thick preapical setae. Abdomen. Dorsa of segments I and II with vaguely defined, transverse rows of 20-24 long, slender setae, spine-like, short setae absent. Dorsa of segments III-VI each with mixture of 85-95 long setae and 70-90 spine-like, short setae. Dorsa of segments VII-IX with about 75 long, slender setae and 70 short, spine-like setae, progressively spaced toward posterior borders of each segment. Dorsum of segment $X$ with spine-like setae on anterior half and mixture of 40-42 long, slender setae and about 80 short, spine-like setae on posterior half. Venter of abdominal segments I-II each with 4 rows of 25-30 long, slender setae, and 2 rows of 20-24 medium sized slender setae; venter of segments III$\mathrm{V}$ each with 1 row of 15 long, slender setae, and 2 rows of 15-20 medium sized, slender setae; venter of segments VI-VIII each with 50-54 long and medium sized, slender setae on each side; venter of segment IX with 50 long and medium sized, slender setae on each side. Raster without pallidia and septula (Fig. 65), with 12-14 long, slender setae on campus, teges formed by 20-24 medium sized, slender setae; cuticle slightly rugose. Barbula formed by $20-25$ long, slender setae. Lower anal lip with about 120 mixed long and short, slender setae. Upper anal lip with more than 100 mixed short and long, slender setae, mainly on sides. Spiracles of segments I-VIII progressively shorter $(0.7-0.5 \mathrm{~mm}$ long; $0.9-0.6 \mathrm{~mm}$ wide); lobes of respiratory plate separated (Fig. 63), directed anteriorly. Spiracular bulla slightly convex, irregularly rounded, weakly prominent (Fig. 62); respiratory plate with about 32 irregularly shaped holes across any diameter. Approximate dorsal body length $65-67 \mathrm{~mm}$.

Second-instar Larva. Based on one second-instar larva reared from egg laid by female collected in México: Baja California, Rosario de Arriba, 22-VIII-2002, G. Nogueira, fixed at 190 days age (IEXA).

Description. Similar to third-instar larva except as follows: maximum width of head capsule $4.5 \mathrm{~mm}$. Last antennal segment with 4 dorsal sensory spots. Dorsal and lateral vestiture of thoracic and abdominal segments with distinctive, long, slender setae. Prothoracic spiracles $0.35 \mathrm{~mm}$ wide, $0.20 \mathrm{~mm}$ long. Abdominal spiracles I-VIII progressively shorter $(0.28-0.25 \mathrm{~mm}$ wide, $0.22-0.20 \mathrm{~mm}$ long). Approximate dorsal body length $50 \mathrm{~mm}$.

First-instar Larva. Based on two first-instar larva reared from egg laid by female collected in México: Baja California, Rosario de Arriba, 22-VIII-2002, G. Nogueira, fixed at 19 days age (IEXA).

Description. Similar to second-instar larva except as follows: maximum width of head capsule 2.7-2.8 mm. Sclerotized plates on sides of pronotum absent. Eclosion spine on each side of metanotum small, conical. Thoracic spiracles $0.14 \mathrm{~mm}$ wide, 0.10 $\mathrm{mm}$ long. Abdominal spiracles kidney-shaped, without definite bulla; spiracles I-VIII progressively shorter $(0.14 \mathrm{~mm}$ wide, $0.10 \mathrm{~mm}$ long $)$. Approximate dorsal body length $14-15 \mathrm{~mm}$.

Remarks. Larvae of $M$. cedrosa share similar characters with the larvae of $M$. thersites and M. elephas: 3-4 posterior frontal setae, 2 setae on each side of clypeus, 7-10 setae on posterior border of labrum, and bulla rounded and slightly prominent. Megasoma cedrosa may be distinguished by the presence of 10 frontal setae, reduced number of epicranial setae (10-16 on each side), right chaetoparia with 64-70 setae, 5 maxillary stridulatory teeth, last antennal segment with 4 dorsal sensory spots, dorsa of abdominal segments I and II without spine-like setae, and 12-14 setae on the campus. The increased number of frontal and epicranial setae, 8 maxillary stridulatory teeth, dorsum of abdominal segment II with short, spine-like setae, spiracles of abdominal segments progressively larger toward segment VIII, lobes of respiratory plate of spiracles contiguous, and increased head and body size will distinguish the larvae of M. elephas from M. cedrosa.

Distribution and Habits. Megasoma cedrosa $(=$ M. lenczyi Cartwright) has been recorded in a small number of localities in Baja California, México, including the type locality on Cedros Island, San Felipe, Rosario de Arriba, and the vicinity of El Progreso 
between 100-600 meters in elevation (Hardy 1972; Cartwright 1976). Adults have been collected from August to October on thorn shrubs, under soil, or on branches of Acacia sp. (Mimosaceae)(Fig. 66). Males are active during the morning, but near noon they walk to the base of the trunk and dig holes in the soil for protection when the air temperature becomes extreme. When the air temperature decreases, males return to the branches of their host tree for gumming sap from the branches or to await the emergence of females (G. Nogueira, pers. comm., to MAM; R. Cunningham, pers. comm., to BCR).

\section{Megasoma elephas (F.), 3rd instar}

(Figs. 67-80)

Description based on three third instar larvae reared from eggs laid by female collected in México: Quintana Roo, Felipe Carrillo Puerto, 26-XII-1984, O. Canul (IEXA); one cast skin of third instar larva with same data (IEXA); two third instar larvae collected in México: Chiapas, Ocosingo, Yaxchilán, 27/28-V-1981, 120-140 m, E. Fuentes (IEXA); one cast skin of third instar larva reared to pupa, collected in México: Chiapas, Cacaohatán, Finca San José de la Victoria, 31-VIII-1981, J. Valenzuela (IEXA).

Description. Head. Maximum width of head capsule 15.6-17.2 mm. Surface of cranium dark brown to black, coarsely rugopunctate, punctures deep. Frons uniformly punctate (Fig. 67), each side with 4 posterior frontal setae, 70-80 anterior frontal setae, 3 exterior frontal setae, 6-7 centrolateral setae, and 6 anterior angle frontal setae; remaining cranial surface with 4 dorsoepicranial, short setae, 45-60 epicranial setae, and 8-10 paraocellar setae on each side. Clypeus trapezoidal, with 2 lateral setae on each side, 10-12 anterior setae, 40-50 discal setae, and 10-12 posterior clypeal setae. Labrum slightly asymmetrical, rounded at sides, with 4-6 scattered, anterior labral setae, 10 posterior setae, 4-5 central setae, and 4-5 lateral setae on each side. Ocelli vaguely indicated. Epipharynx (Fig. 68) with fused zygum and epizygum forming strongly raised, nearly longitudinal, sclerotized tubercle on haptomerum; heli and plegmatia absent; right chaetoparia with mixture of 92-120 spine-like setae and 25-35 sensillae; left chaetoparia with mixture of 70-90 spine-like setae and sensillae; acroparia with 6-10 straight, long, thick setae on right side and 4-6 straight, long, thick setae on left side; both acanthoparia with vaguely indicated, abraded tormae of 8-9 setae; both gymnoparia wide, sclerotized, abraded; pedium wide, epitorma poorly defined; dexiotorma wide, angular, with enlarged and narrowed inner side; laeotorma with enlarged and narrowed inner side, and widely rounded pternotorma; dexiophoba formed by 8-12 setae located near haptolochus; laeophoba between haptolachus and inner side of laeotorma formed by $10-16$ setae; sclerotized plate or right nesium elongate, strongly sclerotized and strongly raised; sense cone of left nesium represented by large, longitudinal, well-sclerotized plate with rounded anterior side and truncate posterior side; crepis indicated by weak, poorly sclerotized shallow sulcus. Scissorial area of right mandible (Fig. 69) slightly abraded, with 3 scissorial teeth clearly separated by notches or sinuses, and 1 basal, rounded tooth; molar area with 3 poorly defined lobes, calx prominent, brustia sparse. Scissorial area of left mandible (Fig. 70) slightly abraded, with 3 scissorial teeth vaguely separated by notches or sinuses, and 1 basal wide, rounded tooth; molar area with 2 wide lobes, brustia sparse, acia short with rounded apex. Stridulatory area of each mandible well-marked by almost 35-40 fine striae. Mala (Fig. 71) with apical uncus of galea well-developed with 3 conical unci fused at their bases at apex of lacinia; maxillary stridulatory area (Fig. 72) with irregular row of 8 wide, truncated or rounded teeth, and wide, truncate anterior process. Labium (Fig. 71) with numerous long, strong setae located near sides and short, spine-like setae at middle and proximal border; hypopharynx with right anterior lateral process of hypopharyngeal sclerome moderately developed, raised, curved, heavily sclerotized; left hypopharyngeal lateral lobe with patch of 8-10 posterior lateral short setae, and 1 line of 20 slender setae. Last antennal segment on dorsal surface (Fig. 73) with 8-10 sensory spots; ventral surface with 10-12 spots. Thorax. Pronotum with wide, irregular, reddish brown, lateral scleromes, each with row of 20-25 long setae (Fig. 77) and about 70-80 long, slender setae near anterior and posterior borders, setae not arranged in definite rows. Mesonotum with transverse group of 48-52 long, slender setae, 80-90 long, slender setae in irregular rows, and 1 group of 40-45 slender setae on each side; metanotum with 2 

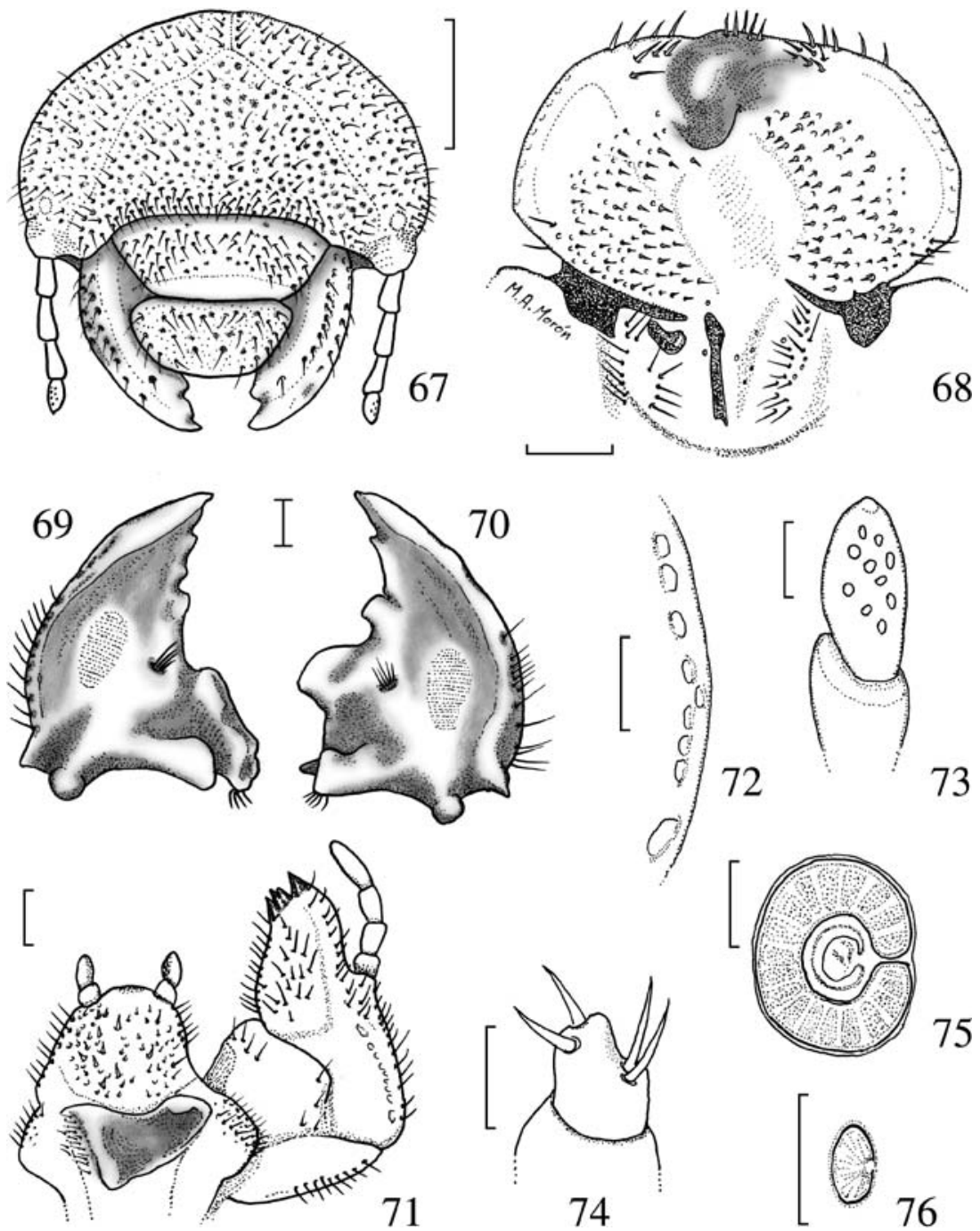

Figs. 67-75. Megasoma elephas, third instar. 67) Head, frontal view; 68) epipharynx; 69-70) mandibles, ventral view; 69) right and 70) left; 71) right maxilla and hypopharynx, dorsal view; 72) detail of maxillary stridulatory area; 73) distal segment of antenna, dorsal view; 74) right posterior tarsal claw, external view; 75) second right abdominal spiracle. Fig. 76. Megasoma elephas, first instar, second right abdominal spiracle. Figs. 67-71, 75, bar $=1 \mathrm{~mm}$. Figs. 72-74, 76 , bar $=0.5 \mathrm{~mm}$.

transverse groups of 40-50 long, slender setae, and 44-52 long, slender setae arranged in irregular row. Thoracic spiracles $1.8-2.2 \mathrm{~mm}$ long and $2.25-2.70 \mathrm{~mm}$ wide; lobes of respiratory plate contiguous, directed posteriorly. Spiracular bulla rounded, convex, irregular, scarcely prominent. Tarsal claws (Fig. 74) similar on all legs, with rounded apex, each bearing 2 internal, long, thick, basal setae and 2 external, long, thick, preapical setae. Abdomen. Dorsum of segment I with 1 row 


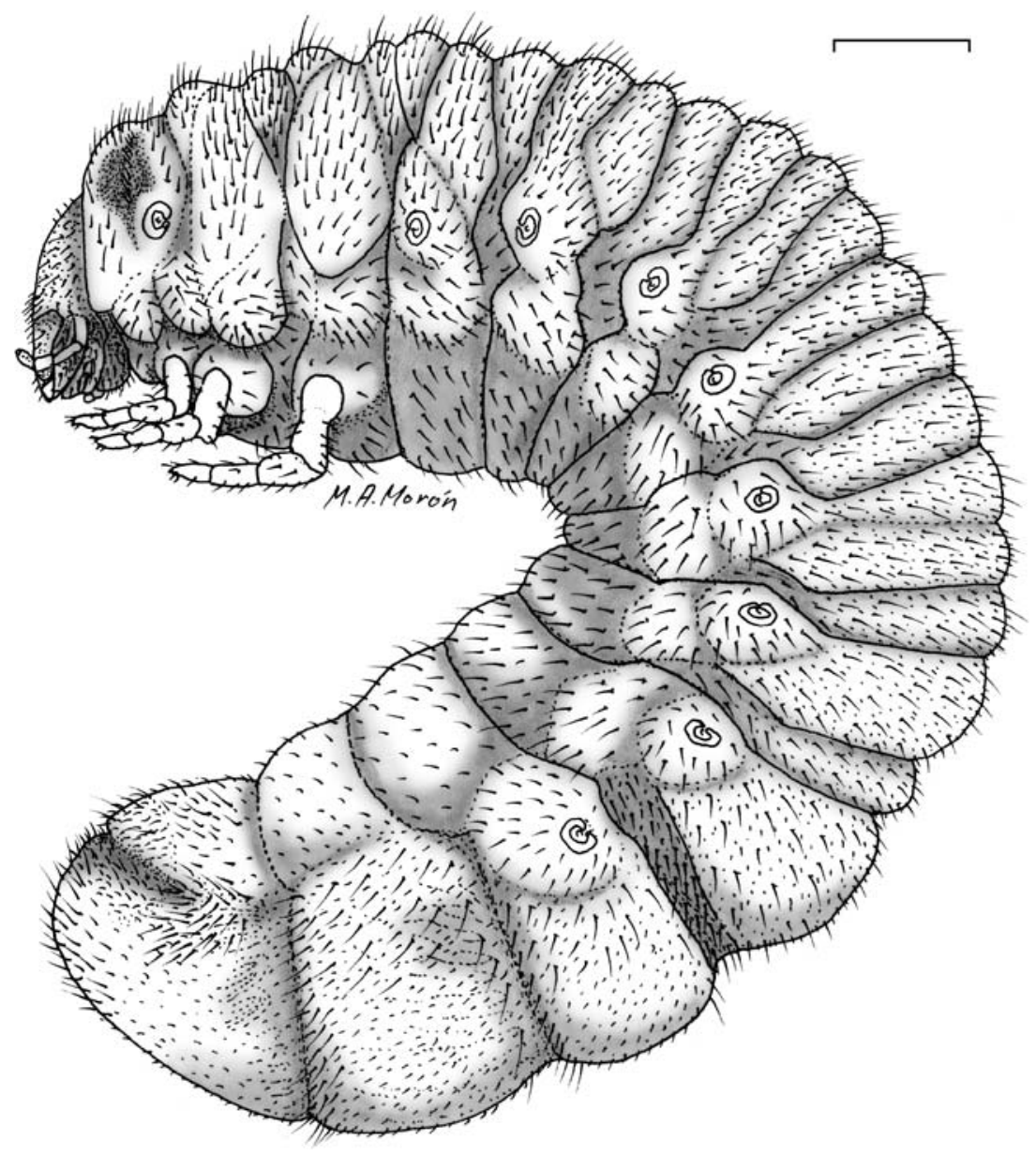

Fig. 77. Megasoma elephas, third instar, lateral view. Bar $=10 \mathrm{~mm}$. Setal pattern simplified.

of 70-75 mixed, medium sized and long, slender setae, and 1 row of 140-150 long, slender setae. Dorsum of segment II with 1 transverse group of 70-80 long, slender setae mixed with 130-140 short, spine-like setae, 1 transverse group of 12-14 long, slender setae mixed with 80-90 short, spine-like setae, and 1 transverse group of 100-120 long, slender setae mixed with 140-160 short, spine-like setae. Dorsa of segments III-VI each with 1 transverse group of 30-32 long, slender setae mixed with 120-130 short, spine-like setae, 1 transverse group of 6-8 long, slender setae mixed with 70-80 short, spine-like setae, and 1 transverse group of 50-56 long, slender setae mixed with 140-150 short, spine-like setae. Dorsum of segment VII with 1 transverse group of 120-130 long, slender setae mixed with 130-140 short, spine-like setae, and 1 transverse group of 60-70 long, slender setae mixed with 70-80 short, spine-like setae. Dorsum of segment VIII (Fig. 73) with 1214 long, slender setae on each side, 8-10 long, slender setae near anterior border, 70-76 long, slender setae near posterior border, and more than 200 short, spine-like setae widely distributed. Dorsum of segment IX with longitudinal rugosities and 12 long, slender setae near anterior border, 20 long, slender setae on each side, 50-60 long, slender setae near posterior border, and more than 250 short, spine-like setae widely distributed. Dorsum of segment X with 20 long, slender setae 


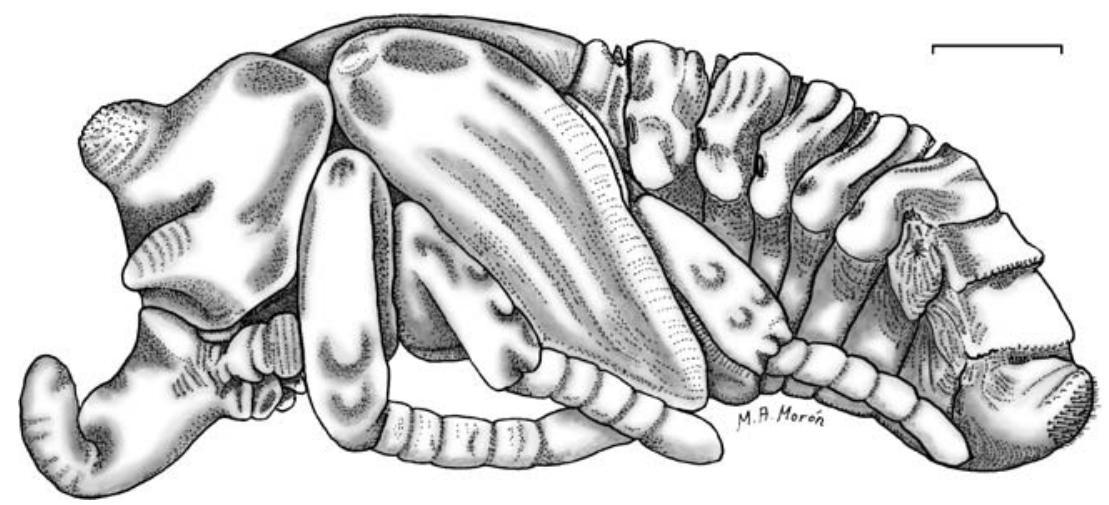

Fig. 78. Megasoma elephas, male pupa, lateral view. $\mathrm{Bar}=10 \mathrm{~mm}$.

near posterior border, 8 medium sized, slender setae scattered at center, and more than 160 short, spine-like setae widely distributed. Venter of abdominal segments I-VI each with irregular rows of 40-50 mixed, long and short, slender setae; venter of segments VII-VIII each with irregular rows of 40-45 mixed, long and medium sized, slender setae; venter of segment IX with groups of 50-60 mixed, long and medium sized, slender setae on each side. Raster without pallidia and septula, with 4-6 medium sized, slender setae on campus, teges formed by 32-35 short, slender setae; cuticle clearly rugose. Barbula formed by 22-25 long, slender setae. Lower anal lip with about 80-86 mixed, long and medium sized, slender setae. Upper anal lip with 260-280 mixed, short and medium length and short, spine-like setae. Spiracles of segments I-VIII (Fig. 77) progressively enlarged (2.10-2.80 mm long; $1.35-2.40 \mathrm{~mm}$ wide); lobes of respiratory plate contiguous (Fig. 75) directed anteriorly. Spiracular bulla convex, irregularly rounded, weakly prominent; respiratory plate with about $90-95$ irregular shaped holes across any diameter. Approximate dorsal body length $125-225 \mathrm{~mm}$.

Second-instar Larva. Based on one second-instar larva reared from egg laid by female collected in México: Quintana Roo, Felipe Carrillo Puerto, 26-XII-1984, O. Canul, fixed at 97 days age (IEXA).

Description. Similar to third-instar larva except as follows: maximum width of head capsule $7.9 \mathrm{~mm}$. Ocelli vaguely indicated. Epipharynx with 8-9 plegmatia finely marked; acroparia with 7-8 straight, long, thick setae on right side, and 4 straight, medium sized, thick setae on left side; both acanthoparia with 10 short, curved, spinelike setae. Scissorial area of both mandibles with teeth more clearly defined. Last antennal segment with 9-13 dorsal sensory spots. Dorsal and lateral vestiture of thoracic and abdominal segments with distinctive, long, slender setae. Prothoracic spiracles $1.0 \mathrm{~mm}$ wide, $0.65 \mathrm{~mm}$ long. Abdominal spiracles slightly enlarged toward posterior segments $(0.75 \mathrm{~mm}$ wide, $0.50-0.70 \mathrm{~mm}$ long). Tarsal claws with 4 long, slender setae. Approximate dorsal body length $60 \mathrm{~mm}$.

First-instar Larva. Based on one first-instar larva reared from egg laid by female collected in México: Quintana Roo, Felipe Carrillo Puerto, 26-XII-1984, O. Canul, fixed at 12 days age (IEXA).

Description. Similar to second-instar larva except as follows: maximum width of head capsule $3.5 \mathrm{~mm}$. Scissorial area of left mandible with second tooth large, dorsally outstanding; scissorial area of right mandible with second tooth triangular, dorsally outstanding. Last antennal segment with 8-9 dorsal sensory spots. Sclerotized plates on sides of pronotum absent. Eclosion spine on each side of metanotum small, conical, surrounded by 4 short, slender setae. Thoracic spiracles $0.25 \mathrm{~mm}$ wide, $0.18 \mathrm{~mm}$ long. 


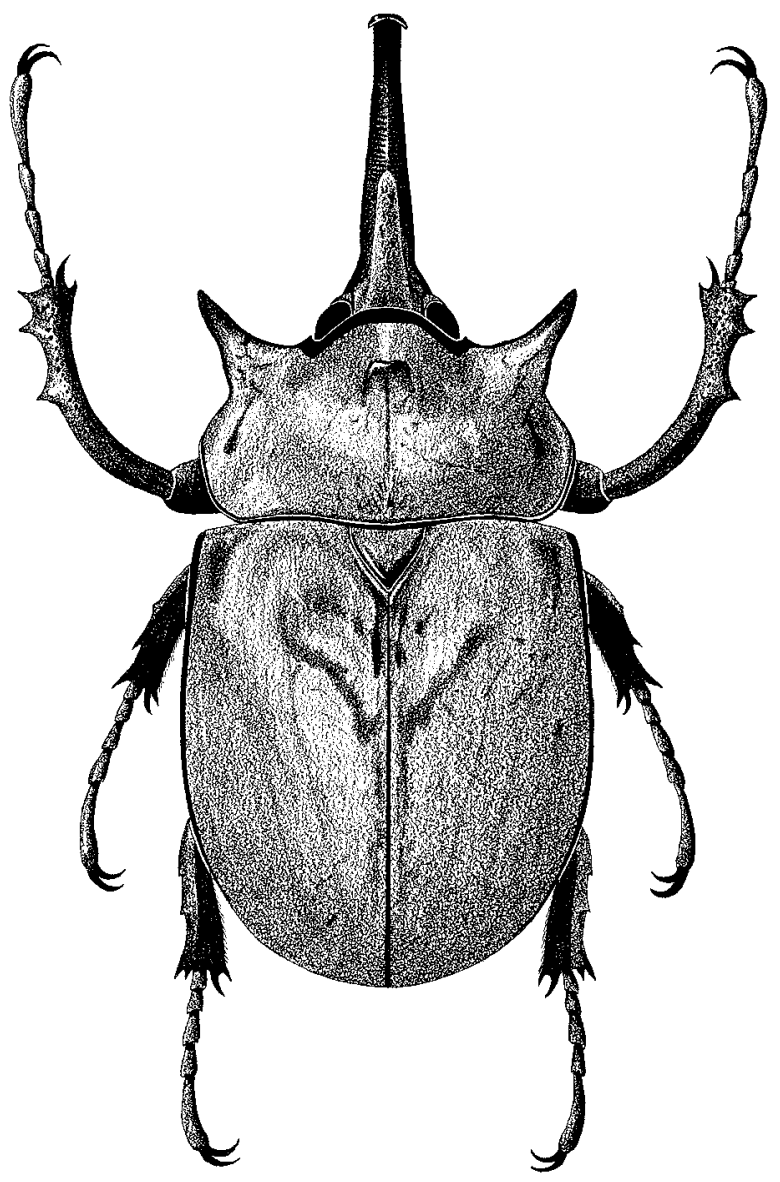

Fig. 79. Megasoma elephas, adult male habitus.

Abdominal spiracles similar in size: $0.21 \mathrm{~mm}$ wide, $0.14 \mathrm{~mm}$ long, without definite bulla (Fig. 76). Approximate dorsal body length $13 \mathrm{~mm}$.

Male Pupa. Based on one pupa reared from third instar larva collected in México: Chiapas, Cacaohatán, Finca San José de la Victoria, 31-VIII-1981, 800 m, coffee-cacao plantation, J. Valenzuela, pupated 27-VI-1982, fixed 1-VII-1982 (IEXA).

Description. Body shape elongate, oval, stout, exarate (Fig. 78). Color dark reddish orange. Entire body with fine, velvety-gold vestiture. Head: Bent sharply beneath thorax, mouthparts directed ventrally; antennae, mandibles, palpi and eye canthus recognizable. Compound eyes sunken, scarcely visible. Frontoclypeus with strong, wide, massive horn-like structure bent upward at distal third, apex widely forked in rounded branches, and anterior surface with fine, transverse ridges. Anterior border of clypeus truncate, with rounded borders. Pronotum: Form nearly transverse, with wide, anteromedial, rounded tubercle, surface finely annulate and with transverse ridges and granules on surface. Each anterolateral border with large, semiconical projection directed obliquely forward, with annulate, fine ridges on surface. Pterothecae closely 


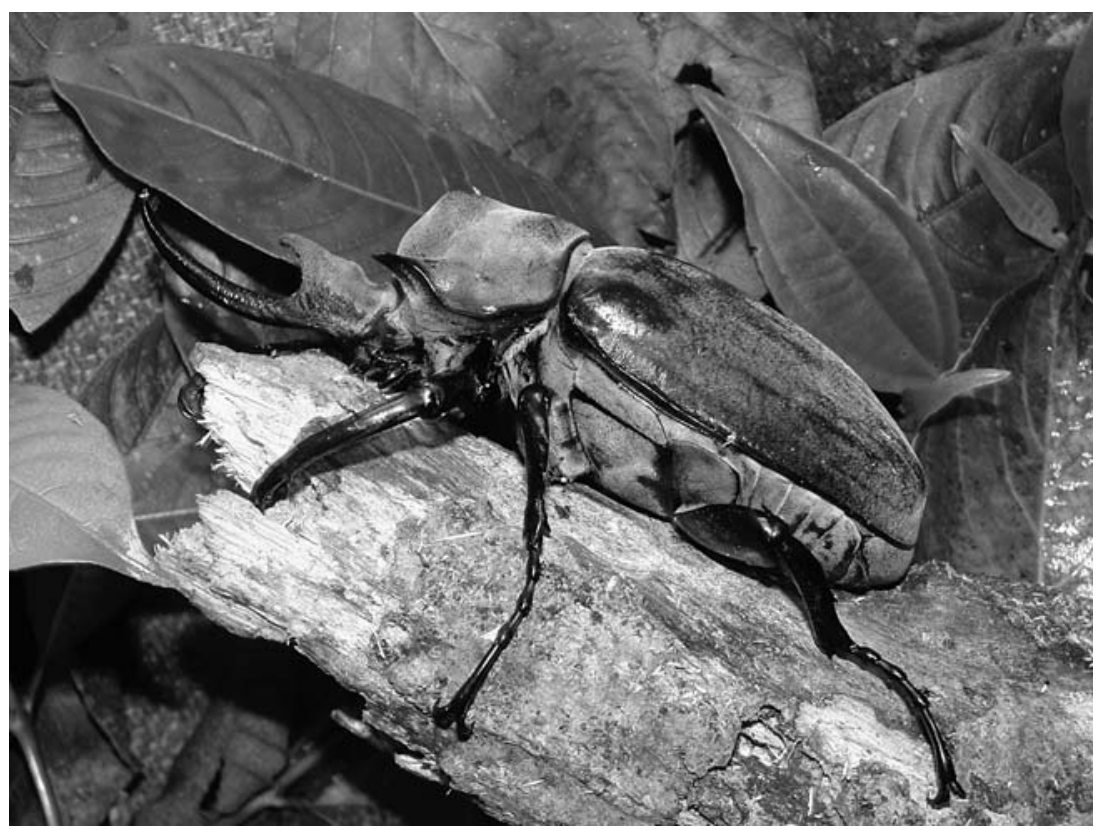

Fig. 80. Adult male Megasoma elephas from Minatitlán, Veracruz, Mexico. Photo by M. A. Morón.

appressed, curving ventrally around body, extending posteriorly to abdominal segment II or III. Legs: Protibia with 3 projections on exterior border. Mesotibia with 2 small tubercles on external side, and 2 apical, rounded tubercles. Metatibia with 3 small, rounded projection on external side, and 2 apical, rounded tubercles. Tarsomeres delineated, protarsi longer that meso- and metatarsi. Abdomen: 9 segments visible. Spiracles of segment I hidden by wing theca and by oblique fold; spiracles on segments II-IV elongate, annulate, sclerotized, pigmented, directed cephalad; spiracles on segments V-VII occluded, rosetiform, not sclerotized or pigmented; spiracle on segment VIII absent. Tergal area of segments I-VI with 6 pairs of deep and wide dioneiform organs or "gin traps" (each 8-9 mm width). Tergum VII with 1 pair of less marked dioneiform organs on anterior border. Tergum VIII with 2 ovate, transverse, deep impressions toward basolateral border. Posterior border of terga VII-VIII with rows of small, rounded tubercles. Last segment with 2 symmetrical, fleshy, ventrolateral folds covered by dense, fine, golden vestiture. Last sternite and genital ampulla partially hidden by folds. Body length $88 \mathrm{~mm}$; maximum width $43 \mathrm{~mm}$.

Female Pupa. Based on cast skin of pupa reared from egg laid 22-I-1985 by female collected in México: Quintana Roo, Carrillo Puerto, 26-XII-1984, O. Canul (IEXA).

Description. Similar to male pupa except that head and pronotum do not have horns or large tubercles; tibiae and tarsi shortened; genital ampulla wide, rounded. Body length not measurable.

Remarks. The third instar larva is robust and measures $34-44 \mathrm{~mm}$ in width between the metathorax and the first two abdominal segments. As a consequence, the head (14-17 $\mathrm{mm}$ in width in frontal view) looks partially sunken into the prothorax and is clearly smaller than it. The larvae of $M$. elephas are similar in a number of structures 
with $M$. occidentalis and M. pachecoi. Shared characters are: number of epicranial setae; 8 maxillary stridulatory teeth; 8-10 dorsal sensory spots on the last antennal segment; 89 setae on each acanthoparia; dorsum of abdominal segment II with short, spine-like setae; abdominal spiracles progressively larger toward segment VIII; lobes of respiratory plate of spiracles contiguous, and bulla of spiracles convex, rounded, and scarcely prominent. Megasoma elephas is easily distinguished from M. occidentalis by the presence of 70-80 anterior frontal setae (4 in M. occidentalis), 4 posterior frontal setae on each side ( 2 in $M$. occidentalis), dorsum of abdominal segment I without short, spine-like setae (with these setae in M. occidentalis), and only 4-6 setae on the campus (20-27 in M. occidentalis). Megasoma elephas differs from M. pachecoi in the number of posterior frontal seta, anterior angular frontal setae, and epicranial setae, dorsum of abdominal segment I with spine-like setae, bulla of spiracles raised and acute, and the larger head and body size.

Distribution and Habits. Adults of M. elephas (Figs. 79-80) have been collected in a wide number of localities ranging from southeastern México to Venezuela. On the slopes bordering the Gulf of Mexico, they have been reported from Plan de las Hayas, Veracruz $\left(19^{\circ} 40^{\prime} \mathrm{N}\right)$ to the northern Yucatan peninsula, and along the Caribbean slopes from Quintana Roo and Belize to Colombia and Venezuela. On the slopes of Pacific Ocean, they have been collected from the Soconusco area in Chiapas, México to the Canal Zone in Panama (Ratcliffe and Morón 1997; Morón and Gómez-Anaya 2002). The habitat for $M$. elephas is tropical evergreen forests, tropical deciduous forests, tropical plantations, and some small remnants of tropical forests located between sea level and 1,000 meters in elevation.

Males and females are active from September to January and are commonly attracted to lights between $2100-2300 \mathrm{~h}$. They fly primarily during the night when the relative humidity nears $98-100 \%$ and the temperature is $20.5-22^{\circ} \mathrm{C}$ (Morón 1979). Numerous adults have been observed in January feeding during daylight hours on twigs and flowers of "machiche" (Lonchocarpus castilloi Standl., Fabaceae) near Xpujil, Calakmul, Campeche, México (P. Reyes, pers. comm., to MAM) and on the flowering tree Lonchocarpus sp. (?) in Guanacaste, Costa Rica (A. Solís and F. Chacón, pers. comm., to MAM). Near Mercedes de Guasimo, Limón, Costa Rica, this species is abundant, and adults have been observed feeding on the sap flows of recently cut twigs of "tangerine" (Citrus nobilis Lour., Rutaceae). During the night, they cut a twig with the aid of both foretibiae crossed as a scissors and turn around many times so that the twig is broken (B. Kohlmann, pers. comm., to MAM).

Larvae have been found inside unidentified rotten stumps in coffee-cacao plantations near Cacaohatan, Chiapas (J. Valenzuela, pers. comm., to MAM); under bark of "jobo" (Spondias mombin L., Anacardiaceae) rotten log placed in tropical rain forest near Yaxchilán, Chiapas (E. Fuentes, pers. comm., to MAM); and inside a hollow near the top of standing trunk of Cedrela mexicana Roem. (Meliaceae) growing near Escárcega, Campeche (D. Cibrián, pers. comm., to MAM). Nine larvae were reared from eggs laid by a female collected at lights in Carrillo Puerto, Quintana Roo, that coupled in captivity with males obtained at the same locality. Two of these larvae (a male and female) completed their development after 630 and 900 days respectively, while feeding on a mixture of milled wood, dry cow dung, and forest soil. Third instar larva of $190 \mathrm{~mm}$ in dorsal length may reach a live weight of $86 \mathrm{~g}$ (Morón and Deloya 2001).

It is also interesting to note that, notwithstanding that adults of $M$. elephas are frequently attracted to lights in high numbers in some Mexican localities, systematic searching in rotten logs and stumps rarely revealed larvae of this species. Inasmuch as adults possibly remain in the canopy and upper branches of trees, it is entirely possible that adult females search for hollows in the upper parts of live trees or dead, standing, large trunks in which to oviposit. Such hollows are formed or enlarged by nesting birds 
or mammals or are remains of partial damage caused by strong winds or lightning strikes that break the top of a trunk or large branches. These hollows are abundant at heights of 8 or more meters from the forest floor. The hollows are progressively filled with organic debris, thus forming a rich organic soil or compost that is an excellent rearing medium for many scarab beetles and other arthropods. It is highly possible that females of $M$. elephas lay eggs in these natural cavities that provide food, stable microclimate, and protection for developing larvae. Second and third instar larvae may also eat the rotten walls of the wood cavity, enlarging the cavity and adding an abundant quantity of fecal pellets that then provide more nitrogenous nutrients to the compost for a subsequent generation of beetles. Pupation would also occur in such hollows, and emerging adults could live in the canopy without need to visit the forest floor. This way of life could explain why we find only occasional $M$. elephas larvae in rotten logs on the forest floor that were perhaps in recently fallen trunks or branches occupied by these larvae during the previous $2-3$ years when the trunk was standing. We have some evidence to support the idea that females do not lay eggs in fallen tree trunks on the forest floor. One of us (MAM) and other colleagues have sampled numerous rotten logs in areas where adults are known to be abundant, but we never found eggs, larvae, pupae, or fresh remains of adult females.

\section{Megasoma actaeon (L.), 3rd instar}

(Figs. 81-93)

Description based on one third instar larva reared from eggs laid by female collected in French Guyana (1992) and one cast skin of lab-reared, third instar larva (1997) (UNSM).

Description. Head: Maximum width of head capsule $15.1 \mathrm{~mm}$. Surface of cranium dark reddish brown, coarsely rugopunctate (Fig. 81); punctures large, dense, deep. Frons on each side with 4 short, posterior frontal setae, 8 short, anterior frontal setae, and 2 long anterior angle frontal setae; remaining cranial surface on each side with 10 dorsoepicranial setae, 7-10 minute epicranial setae, and 6 long, paraocellar setae. Clypeus trapezoidal, with 1 long, posterior clypeal seta near each lateral margin. Labrum slightly asymmetrical, rounded at sides, with 2 long, setae on each side, and 18 long setae in transverse row in basal third. Ocelli vaguely indicated. Epipharynx (Fig. 82) with fused zygum and epizygum forming raised, longitudinal, sclerotized tubercle on haptomerum; heli and plegmatia absent; right chaetoparia with about 75 spine-like setae and 15 sensillae; left chaetoparia with about 75 spine-like setae and 25 sensillae; acroparia with 9 long, thick setae on right side and 6 long, thick setae on left side; both acanthoparia with vaguely indicated (nearly obsolete) tormae of about 4 setae; both gymnoparia wide, weakly sclerotized; pedium wide; dexiotorma wide, elongate; laeotorma slender, elongate, with widely rounded pternotorma; dexiophoba with 15 long setae located near haptolochus; laeophoba with 10 long setae sclerotized plate of left nesium elongately subtriangular, strongly sclerotized; sense cone of left nesium represented by large, longitudinal, well-sclerotized plate with suboval anterior end and truncate posterior end; crepis vaguely indicated by shallow sulcus. Scissorial area of right mandible (Figs. 84-85) with 3 scissorial teeth vaguely separated by notches and 1 small, basal, angular tooth; molar area (ventral view) with 3 poorly defined lobes, calx prominent, brustia sparse. Scissorial area of left mandible (Figs. 83, 86) with 3 scissorial teeth distinctly separated by notches and 1 basal, wide, subquadrangular tooth; molar area with 1 feeble lobe, brustia sparse, acia low and rounded. Stridulatory area of each mandible with about 14 well-marked striae, striae broad basally, becoming finer apically. Mala (Fig. 87) with large, apical uncus on galea and with 3 well-developed unci fused at their bases at apex of lacinia; maxillary stridulatory area (Fig. 88) with short row of 4 laterally compressed, semi-oval teeth and heavily sclerotized, narrowly elongate anterior process. Labium (Fig. 86) with numerous, long setae located on sides, slightly shorter setae near lateral margins, and minute sensillae at center near base; hypopharynx with right anterior process of hypopharyngeal sclerome moderately developed, raised, heavily sclerotized. 

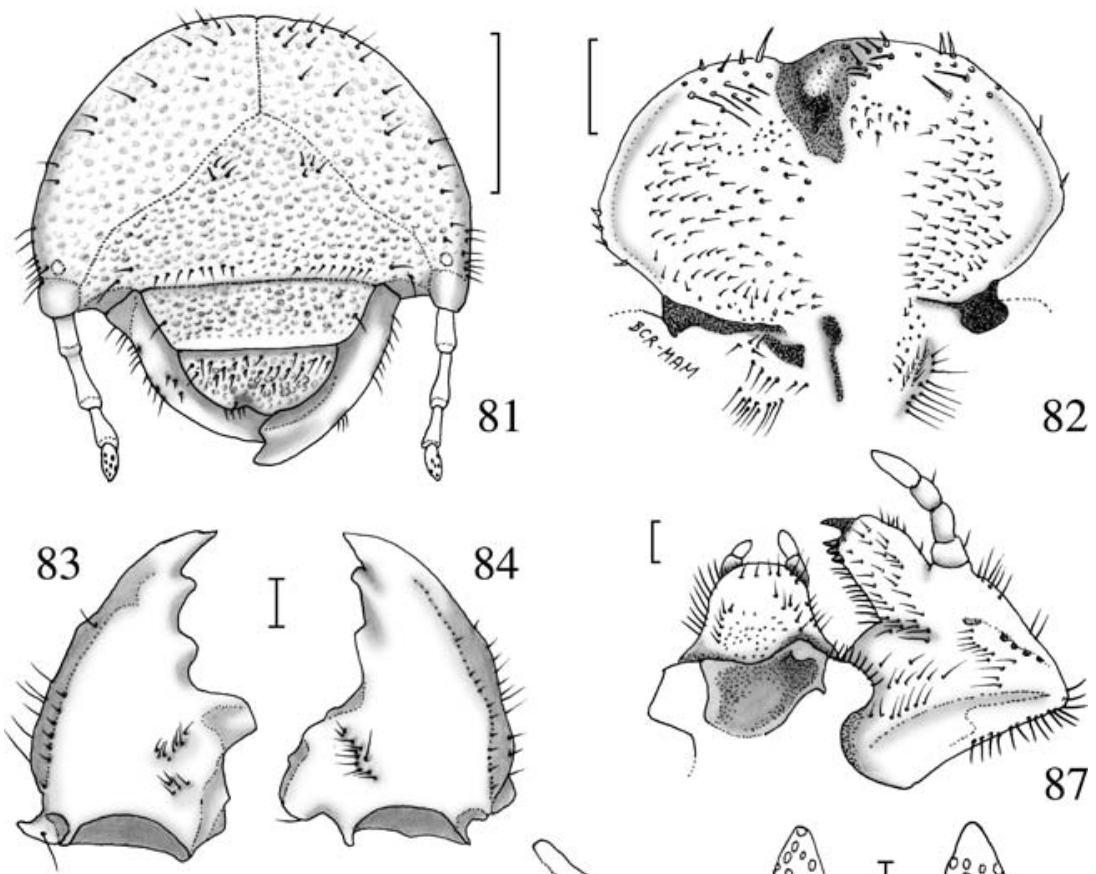

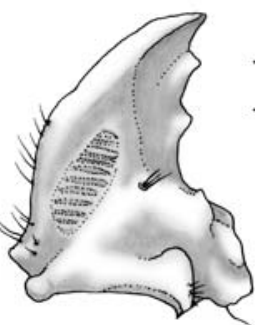

85

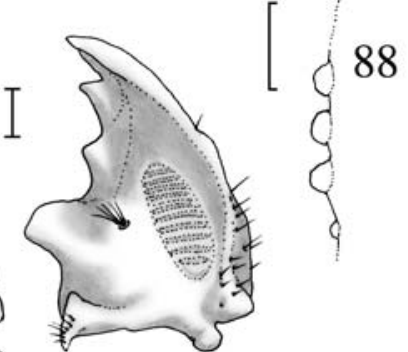

86

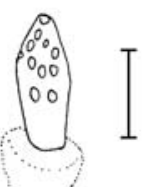

89

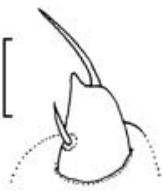

91

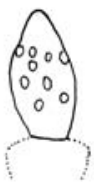

90

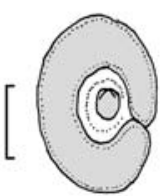

92

Figs. 81-92. Megasoma actaeon, third instar. 81) Head, frontal view; 82) epipharynx; 83-84) mandibles, dorsal view, 83) left and 84) right; mandibles, ventral view, 85) right and 86) left; 87) right maxilla and hypopharynx, dorsal view; 88) detail of maxillary stridulatory area; 89) distal segment of antenna, dorsal view; 90) distal segment of antenna, ventral view; 91) left middle tarsal claw, anterolateral view; 92) second right abdominal spiracle. Fig. 81, bar $=5 \mathrm{~mm}$. Figs. 82-87, $89-90,92$, bar $=1 \mathrm{~mm}$. Figs. 88, 91, bar $=0.5 \mathrm{~mm}$.

Last antennal segment on dorsal surface (Fig. 89) with 11 sensory spots; ventral surface (Fig. 90) with 9 spots. Thorax: Pronotum with irregularly shaped, reddish brown, lateral sclerome with vertical row of 10 long setae, and about 110 mostly long setae near anterior margin, and about 100 long setae near posterior margin, setae not arranged in rows. Mesonotum with transverse group (briefly interrupted at middle) of about 70 long, slender setae, and 50 long, slender setae in irregular rows and a group of 75 long, slender setae on each side; metanotum with 2 transverse groups of 35 and 50 long, slender setae on each side and about 75 other long, slender setae on 


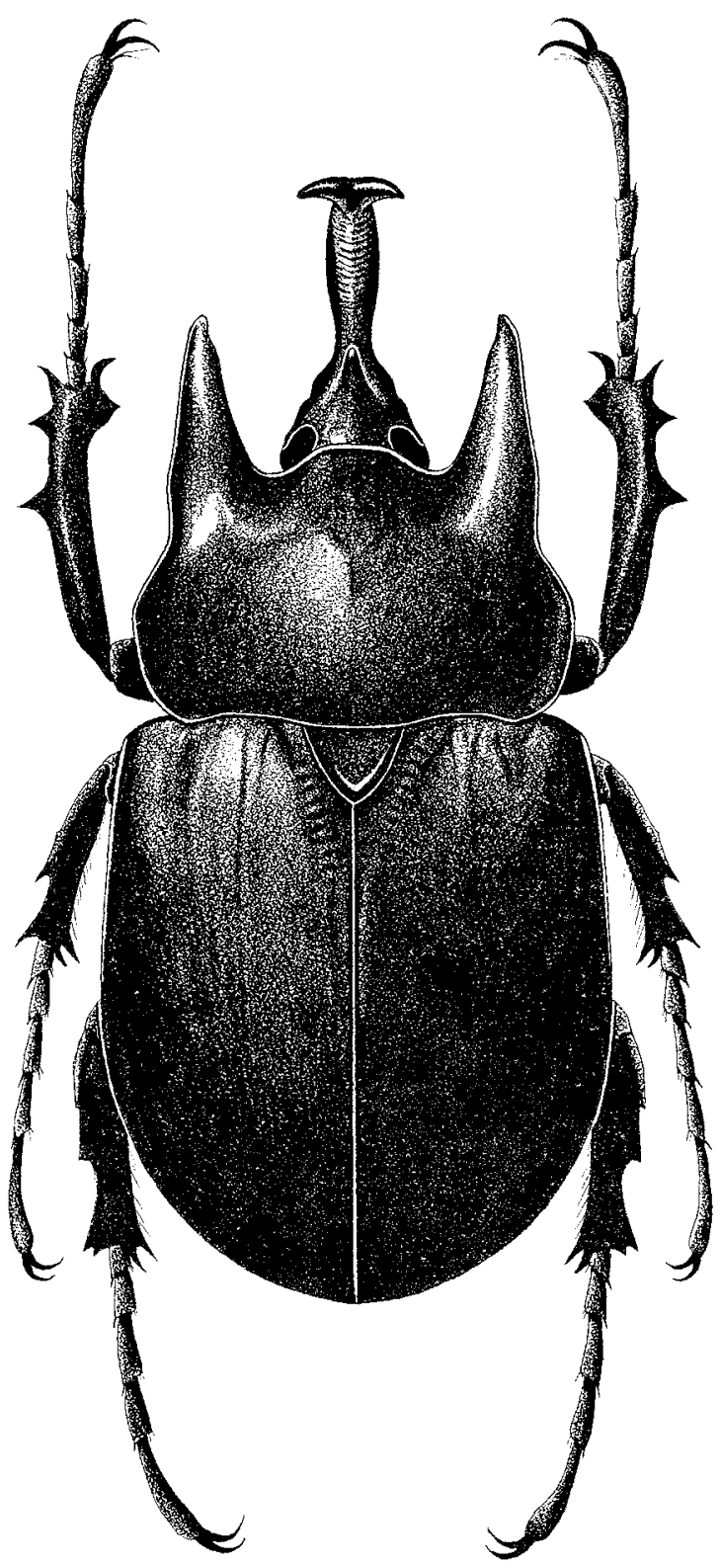

Fig. 93. Megasoma actaeon, adult male habitus.

each side. Thoracic spiracle $2.7 \mathrm{~mm}$ long and $2.0 \mathrm{~mm}$ wide; lobes of respiratory plate contiguous, directed posteriorly. Spiracular bulla rounded, irregularly convex, prominent. Tarsal claws (Fig. 91) similar on all legs, with rounded apex bearing a sclerotized tooth and with 1 long, slender seta on median side and 1 short, thick seta on outer side. Abdomen: Dorsum of segment I with 
transverse row of 40 mixed, medium sized and long, slender setae and 1 row of about 70 long, slender setae and 40 sort, spine-like setae. Dorsum of segment II on prescutum with 1 transverse group of about 100 long, slender setae mixed with about 80 short, spine-like setae; scutum with about 16 long, slender setae mixed with about 110 short, spine-like setae; postscutum with about 36 long, slender setae mixed with about 120 short, spine-like setae. Dorsa of segments III-VI each with 1 transverse group of about 40 long, slender setae mixed with about 160 short, spine-like setae on prescutum; scutum with 6 long, slender setae mixed with about 140 short, spine-like setae; postscutum with about 30 long, slender setae mixed with about 210 short, spine-like setae. Dorsum of segment VIII with anterior transverse row of 8 long, slender setae and posterior transverse row of about 44 long, slender setae and about 80 long, slender setae on sides surrounding spiracle and about 120 short, spine-like setae generally distributed, and with a transverse row of about 100 long, slender setae (mostly on sides) near posterior border. Dorsum of segment IX with 2 transverse rows of 14 long, slender setae each, about 75 short, spine-like setae widely distributed, and about 80 long, slender pleural setae. Dorsum of segment $\mathrm{X}$ with about 30 medium sized, slender setae widely distributed, about 150 short, spine-like setae widely distributed and about 150 long, slender setae on posterior border. Venter of abdominal segments I-VI each with about 80 long, slender setae. Venter of segments VII-VIII each with about 50 long slender setae. Venter of segment IX with about 30 long, slender setae either side of middle. Raster lacking pallidia and septula, with about 30 medium sized, slender setae on campus; teges formed by about 65 short, slender setae. Barbula formed by 60 long, slender setae. Lower anal lip with about 90 long, slender setae. Upper anal lip with about 120 short, spine-like setae. Spiracles of segments I-VIII (Fig. 92) progressively larger (2.2-2.8 mm long, $2.0-2.2 \mathrm{~mm}$ wide); lobes of respiratory plate contiguous, directed anteriorly. Spiracular bulla irregularly convex, weakly prominent; respiratory plate with about 90 minute holes across any diameter. Approximate dorsal body length $130 \mathrm{~mm}$.

Remarks. Megasoma actaeon is unique among all of the known species in the genus because it has the fewest number of maxillary stridulatory teeth with only 4 (5-8 in other species) and only 2 setae on each tarsungulus. It is easily separated from the equally large and partially sympatric $M$. elephas by the relatively small and "sunken" head of M. elephas, far fewer cranial frontal setae in M. actaeon, dorsum of the first abdominal segment with a mixture of short and long setae in M. actaeon (long setae only in M. elephas), and by the presence of about 28 long setae on the campus of the last abdominal segment in $M$. actaeon (only 4-6 setae in M. elephas).

Megasoma actaeon differs from the other large (but allopatric) species in Mexico, $M$. occidentalis, by the presence of 8 cranial frontal setae in M. actaeon (4 frontal setae in $M$. occidentalis), last antennal segment with 11 dorsal sensory spots (8 dorsal sensory spots in $M$. occidentalis), and maxillary stridulatory area with only 4 teeth in M. actaeon (8 teeth in M. occidentalis).

Distribution and Habits. Megasoma actaeon is known from Panama, the Guianas, Bolivia, Venezuela, Ecuador, Colombia, Peru, Brazil (primarily Amazonia), and northern Paraguay (Lachaume 1985; Ratcliffe 2003). Like the other large Dynastini, the larvae probably develop in rotting logs. Adults (Fig. 93) are nocturnal and attracted to lights. Radnai (2003) compiled the following life history information based upon six years of observations. Eggs were deposited into a suitable log or compost and were approximately $8-10 \mathrm{~mm}$ long and $7.5 \mathrm{~mm}$ in diameter when laid. After deposit, the eggs increased in size, presumably by absorption of water. Eggs increased in length by $5-7 \mathrm{~mm}$, and the diameter increased by $3.5-5.5 \mathrm{~mm}$. Eclosion took from $25-36$ days.

Upon hatching, first instar larvae measured about $8 \mathrm{~mm}$ in length and $3-4 \mathrm{~mm}$ in diameter. A first instar larva weighed about $0.17 \mathrm{~g}$ whereas a third instar larva will weigh $90 \mathrm{~g}$. Laboratory development time for all three instars averaged 943 days (893 days minimum, 993 days maximum). The prepupal stage took about 24 days after which pupation occurred. Pupation lasted about 38 days. The pupation chamber is comprised of compacted compost about the size of an adult's fist. Total development time averaged 1,035 days (2.8 years). In captivity, adults lived from 100 to 151 days. Lai (2001) 
observed that larvae he reared in captivity preferred to congregate in groups and suggested they live this way in nature.

\section{Megasoma occidentalis Bolívar y Pieltain, Jiménez-Asúa, and Martínez, 3rd instar}

(Figs. 94-106)

Description based on three third instar larvae collected in association with an adult female in Mexico: State of Colima, Tecomán Municipality, El Saucito, 28-VIII-70, Y. Domínguez \& R. Peña, in rotten log of Cocos nucifera L., 200 m (IEXA).

Redescription. Head: Maximum width of head capsule $16 \mathrm{~mm}$. Surface of cranium (Fig. 94) strongly and densely punctate, dark brown to black. Frons on each side bearing 2 posterior frontal setae, 3 median lateral frontal seta, 4 anterior frontal setae, and numerous anterior frontal angular setae of which 1 is distinctly thicker and longer; remaining cranial surface bears numerous short, fine, uniformly distributed setae and 2 conspicuous, dorsoepicranial setae and 4 epicranial setae, all placed well away from epicranial suture. Clypeus with 4 long setae on preclypeus and numerous short, fine, scattered setae. Labrum subtrapezoidal, with 5 or 6 posterior setae, 2 central setae, 4 lateral setae, and numerous short, fine, scattered setae. Ocelli vestigial. Epipharynx (Fig. 95) with fused zygum and epizygum forming oblique, sclerotized tubercle; heli absent; right chaetoparia with 52-55 spinelike setae and 56 fine setae; left chaetoparia with 86-90 spinelike setae and few fine setae; right acroparia with 15-17 straight, long, thick setae; left acroparia with 18-20 long, slightly curved, thick setae; acanthoparia with 9 short, curved, spinelike setae. Scissorial area of right mandible (Fig. 96) with 3 teeth separated by 2 notches; molar area with 3 lobes. Scissorial area of left mandible (Fig. 97) with 3 teeth and 1 truncate pre-incisor tooth; molar area with 2 lobes and long, truncate acia. Stridulatory area of each mandible well-marked by distinct striae. Galea (Fig. 98) with conical uncus well-developed; lacinia with 3 conical unci fused at their bases; maxillary stridulatory area with 8 small, subtrapezoidal, truncated teeth and wide, truncate anterior tubercle (Fig. 98). Labium cylindrical in form (Fig. 99), with numerous long, strong setae located principally at sides; hypopharynx with right anterior lateral process of hypopharyngeal sclerome strongly developed, raised and curved, heavily sclerotized; left hypopharyngeal lateral lobe with oblique row of 7 posterior lateral setae. Dorsal surface of last antennal segment (Fig. 100) with 8 sensory spots. Thorax: Pronotum with wide lateral areas, well-sclerotized and reddish brown. Mesoprescutum with 1 anterior row of short setae and 4 rows of posterior large setae; mesoscutum with 3 lateral rows of long setae; mesoscutellum with 2 rows of long setae; metaprescutum with anterior, irregular row of short setae and 3 posterior rows of long setae; metascutum with 4 lateral rows of long setae; metascutellum with 3 rows of long setae. Thoracic spiracles (Fig. 101) 2.06 $\mathrm{mm}$ long and $1.93 \mathrm{~mm}$ wide. Respiratory plate with indefinite number of irregular-shaped "holes" (Fig. 102), lobes of respiratory plate contiguous. Spiracular bulla convex, longitudinal. Claws (Fig. 103) each with 2 internal, long, thick basal setae and 2 external, long thick preapical setae. Abdomen. Dorsa of segments I-VI each with 3-5 transverse rows of short, spine-like setae; dorsa of segments I-II each with 2-3 transverse rows of long, spinelike setae; dorsa of segments III-VI each with transverse row of long, spinelike setae; dorsum of segment VII with 8-9 transverse rows of short, spinelike setae, 1 anterior row of long, fine setae, 1 subposterior row of long, fine setae, and 1 posterior row of long, fine setae; dorsum of segment VIII with 7-8 transverse rows of short, spinelike setae, some scattered anterior long, fine, setae, 1 subposterior row of long, fine setae, and 1 posterior row of long, fine setae; dorsum of segment IX with anterior scattered, short, spinelike setae, 1 anterior row of long, fine setae, and 1 posterior row of long, fine setae; dorsum of segment $\mathrm{X}$ with scattered short, spinelike setae and long, fine setae (pleural lobes of all abdominal segments densely covered with setae). Venter of abdominal segments I-IX each with 1 median, transverse row of long fine setae. Raster (Fig. 104) with 22-27 long, fine setae in campus; teges with 40-44 scattered, long, fine setae; lower anal lip with 78-86 fine setae; upper anal lip with numerous mixed short, spinelike setae and long, fine setae; setae of barbula sparse. Dorsolateral region of segment X (dorsally adjacent to outer extremity of anal slit) with light, cribrate, subtriangular depression (Fig. 105). Spiracles of segments I-VIII progressively larger (2.0-3.0 mm long and $1.8-2.0 \mathrm{~mm}$ wide). Approximate dorsal body length $90-100 \mathrm{~mm}$. 

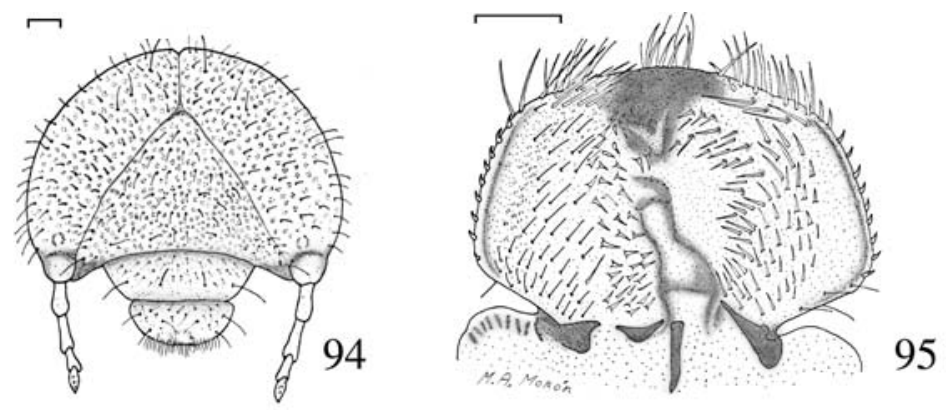

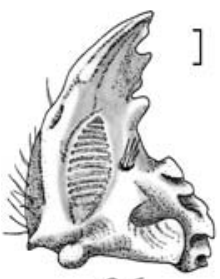

96
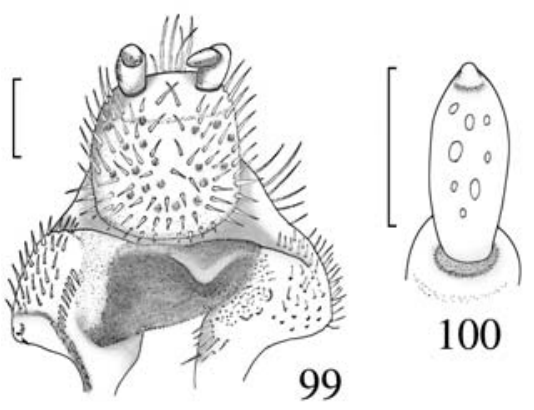

100

99

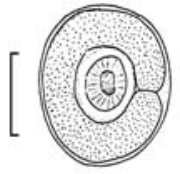

97

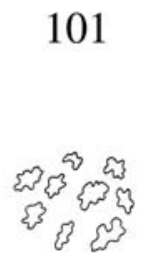

102
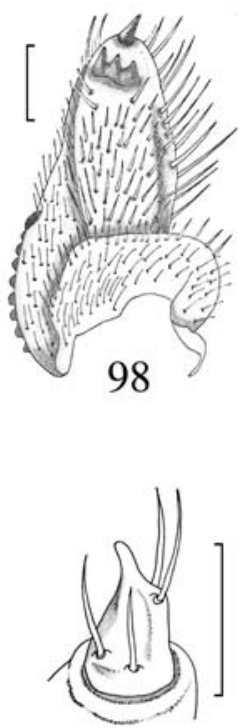

103
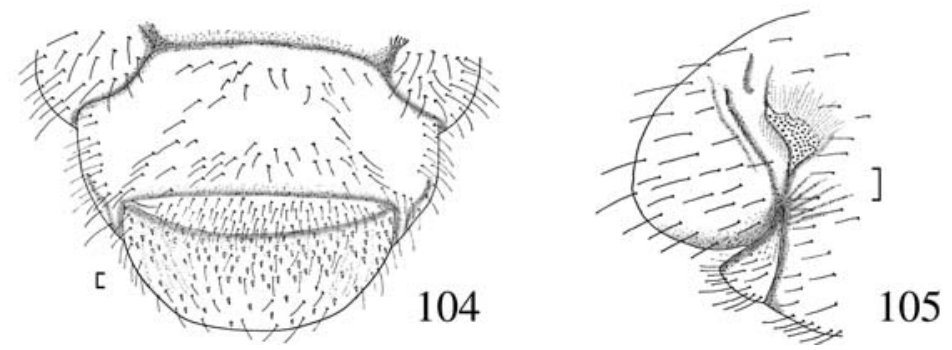

Figs. 94-105. Megasoma occidentalis, third instar. 94) Head, frontal view; 95) epipharynx; 96-97) mandibles, ventral view, 96) right and 97) left; 98) labium and hypopharynx, dorsal view; 99) left maxilla dorsal view; 100) distal segment of antenna, dorsal view; 101) thoracic spiracle; 102) structure of holes of respiratory plate; 103) left prothoracic claw, lateral view; 104) venter of segment $X$ of abdomen; 105) last abdominal segments, lateral view. Bar $=1 \mathrm{~mm}$ for all figures except Fig. 102. 


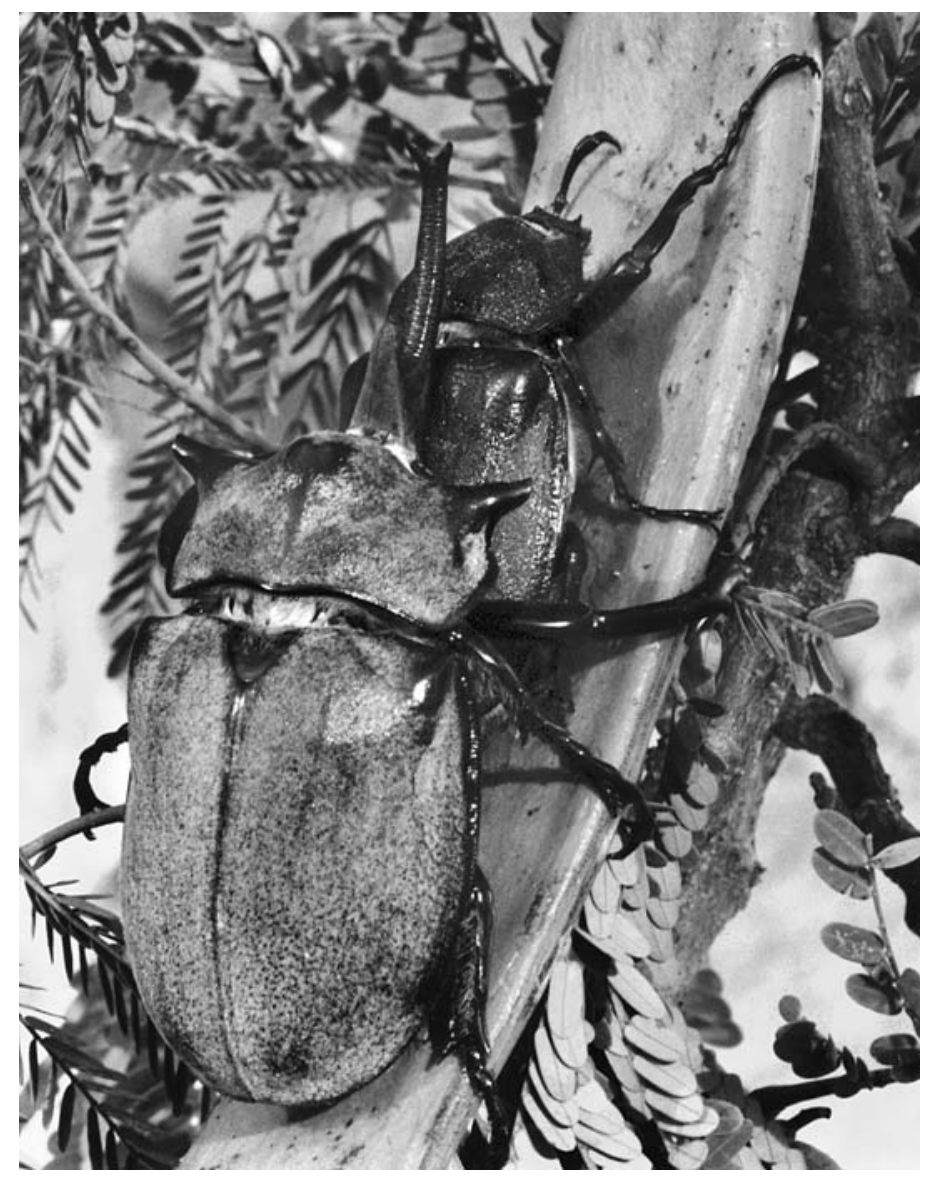

Fig. 106. Megasoma occidentalis, adult male, on fruit of Delonyx regia (Bojer) Raf. (Fabaceae), Puerto Vallarta, Jalisco, Mexico. Photo by G. Nogueira.

Remarks. Larvae of M. occidentalis are characterized by 9 spines on acanthoparia; right laterocentral part of anterior border of labrum not sinuous; ocelli vague; maxilla with 8 stridulatory teeth; last antennal segment with 8 dorsal sensory spots; anterior abdominal spiracles smaller than posterior spiracles; more than 50 "holes" in respiratory plate; 2-12 rows of setae on abdominal dorsa; setae of barbula sparse; campus with 22-27 setae.

Distribution and Habits. Adults of M. occidentalis (Fig. 106) have been collected on the slopes of Pacific Ocean from southern Sinaloa (Mazatlán) to Oaxaca (Pochutla) México $\left(19^{\circ} 40^{\prime} \mathrm{N}\right)$ (Ratcliffe and Morón 1997; Morón and Gómez-Anaya 2002). The habitat for $M$. occidentalis is tropical deciduous forests and tropical plantations located between sea level and 700 meters in elevation. Larvae were also found inside the rotten stem of a coconut palm in plantations near Tecomán, Colima (Morón 1977). Adults of M. occidentalis are frequently attracted to lights in high numbers in some Mexican localities, but searching for larvae in rotten logs and stumps has not revealed them. It 
may be possible that the life history and habits of this species are similar to those of M. elephas. Attempts to rear them from eggs in the lab were unsuccessful.

\section{Key to the Third Instar Larvae of Megasoma in North and Central America}

1 Maxilla with 4 or 8 stridulatory teeth. Diameter of abdominal spiracles progressively enlarged posteriorly, mainly from segment $\mathrm{V}$ to segment VIII. Maximum width of cranium 11-18 mm … . . . . . . . . 2

1' Maxilla with 5-7 stridulatory teeth. Diameter of abdominal spiracles progressively reduced posteriorly, mainly from segment V to segment VIII. Maximum width of cranium 7-9 $\mathrm{mm}$

2 Bulla of spiracles transverse, raised, with acute apex (Figs. 12-13). Last antennal segment with 10-14 dorsal sensory spots. Frons with 1 posterior frontal setae on each side. Dexiotorma narrow, elongate (Fig. 2). Maximum width of head capsule

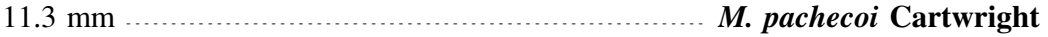

2' Bulla of spiracles vertical, slightly prominent, rounded (Fig. 75). Last antennal segment with 8-11 dorsal sensory spots. Frons with 2-4 posterior frontal setae on each side. Dexiotorma wide, angular (Fig. 68). Maximum width of head capsule

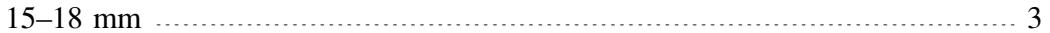

3 Frons with 70-80 frontal setae. Dorsum of abdominal segment I without short, spine-like setae, only with long, slender setae. Campus with 4-6 long, slender setae

M. elephas (F.)

$3^{\prime}$ Frons with 4 or 8 frontal setae. Dorsum of abdominal segment I with mixture of long, slender setae and short, spine-like setae. Campus with 20-28 setae …..... 4

4 Each tarsungulus with 4 setae. Frons with 4 frontal setae. Maxilla with 8 stridulatory teeth. Last antennal segment with 8 dorsal sensory spots

M. occidentalis Bolívar y Peltain, Jiménez-Asúa, and Martínez

4' Each tarsungulus with 2 setae. Frons with 8 frontal setae. Maxilla with 4 stridulatory teeth. Last antennal segment with 11 dorsal sensory spots ......... M. actaeon (L.)

5 Lobes of respiratory plates of spiracles separated (Figs. 39, 62-63). Frons with 3-4 posterior frontal setae on each side. Acanthoparia with 10-14 setae ............... 6

5 ' Lobes of respiratory plates of spiracles contiguous or nearly so (Figs. 26, 5354). Frons with 5-7 posterior frontal setae at each side. Acanthoparia with 5-9 setae …............................................................................ 7

6 Maxilla with 7 stridulatory teeth (Fig. 34). Last antennal segment with 7 dorsal sensory spots (Fig. 36). Dorsa of abdominal segments I-II with mixture of long, slender setae and short, spine-like setae. Frons with 2 dorsoepicranial setae and 46 epicranial setae on each side; anterior frontal setae lacking

M. thersites LeConte

6' Maxilla with 4 stridulatory teeth (Fig. 59). Last antennal segment with 4 dorsal sensory spots (Fig. 61). Dorsa of abdominal segments I-II with only long, slender setae. Frons with 7-10 dorsoepicranial setae and 10-16 epicranial setae on each side, and with 10-11 anterior frontal setae

M. cedrosa Hardy

7 Frons with 6-7 anterior frontal setae. Dexiotorma wide, truncate (Fig. 44). Dorsum of abdominal segment I with mixture of long, slender setae and short, spine-like setae. Bulla of spiracles irregularly rounded, vaguely trilobed (Figs. 53-54). Campus with 18 setae

M. vogti Cartwright

7 ' Frons without anterior frontal setae. Dexiotorma narrow, elongate (Fig. 17). Dorsum of abdominal segment I with long, slender setae, without spine-like setae. Bulla of spiracles slightly convex, rounded (Fig. 26). Campus with 28-30 setae M. punctulatus Cartwright 


\section{Acknowledgments}

We are grateful to the many people who assisted us in our study. Larval specimens were generously donated by William W. Gibson (Stephen F. Austin State University, Nacogdoches, TX), Richard Cunningham (Chino, CA), Barney Streit (Tucson, AZ), William B. Warner (Chandler, AZ), Daniel W. Sundberg (San Antonio, TX), Richard L. Westcott (Salem, OR), Stephane Letirant (Insectarium du Montreal, Canada), Jorge Valenzuela (Xalapa, Veracruz), Guillermo Nogueira (Guadalajara, Jalisco), and Enrique Fuentes (México City). We are also indebted to Bill Warner, Rich Cunningham, Guillermo Nogueira, Cuauhtémoc Deloya (Xalapa), Pedro ReyesCastillo (Xalapa), David Cibrián (Chapingo, México), Bert Kohlmann (Limón, Costa Rica) and Angel Solís (INBio, Costa Rica) for valuable, unpublished data on the biology and habits of Megasoma species. César V. Rojas (Xalapa) and Angie Fox (University of Nebraska State Museum) assisted with digitizing illustrations. Mark Marcuson is acknowledged for the adult habitus drawings. Photographs of live beetles were generously provided by Barney Streit (Tucson, AZ), Richard Cunningham (Chino, CA) and Guillermo Nogueira (Guadalajara, Mexico). This work was supported, in part, by NSF/PEET grants (DEB-9712447) to B. C. Ratcliffe and M. L. Jameson and DEB-0118669 to M. L. Jameson and B. C. Ratcliffe, and an NSF/ BS\&I grant (DEB 9870202) to B. C. Ratcliffe and R. D. Cave.

\section{Literature Cited}

Cartwright, O. L. 1952. A new Megasoma from Arizona (Coleoptera: Scarabaeidae). Proceedings of the Entomological Society of Washington 54:36-38.

Cartwright, O. L. 1963. Two new species of Megasoma from the United States and México (Coleoptera: Scarabaeidae). Coleopterists Bulletin 17:25-29.

Cartwright, O. L. 1970. The male of Megasoma vogti Cartwright (Coleoptera Scarabaeidae: Dynastinae). Proceedings of the Entomological Society of Washington 72:224-226.

Cartwright, O. L. 1976. A new Megasoma from Baja California, México (Coleoptera: Scarabaeidae: Dynastinae). Coleopterists Bulletin 30:85-89.

Endrödi, S. 1977. Monographie der Dynastinae (Coleoptera) 6. Tribus Dynastini. II. Acta Zoologica Academiae Scientiarum Hungaricae 23:37-86.

Endrödi, S. 1985. The Dynastinae of the world. Dr. W. Junk Publishers, Dordrecht. 800 pp., 46 plates.

Gibson, W. W. 1964. Observations on the biology of Megasoma pachecoi Cartwright (Coleoptera: Scarabaeidae) from northwest Mexico. Folia Entomológica Mexicana 7-8: 38-39.

Hardy, A. R. 1972. A brief revision of the North and Central American species of Megasoma (Coleoptera: Scarabaeidae). Canadian Entomologist 104:765-777.

Lachaume, G. 1985. Dynastini 1: Dynastes-Megasoma-Golofa. Les Coleopteres du Monde 5:1-85.

Lai, J. T. 2001. For the love of rhinoceros and stag beetles. Morning Star Publishing, Inc., Tapai, Taiwan. 346 pp.

Möhres-Reitter, J. 1966. Coleopteros. La enigmática vida de los escarabajos. Ediciones DaimonManuel Tamayo, Barcelona, pp. 63-65.

Morón, M. A. 1977. Description of the third-stage larva of Megasoma elephas occidentalis Bolívar et al. (Coleoptera: Scarabaeidae). Coleopterists Bulletin 31:339-345.

Morón, M. A. 1979. Fauna de coleópteros lamelicornios de la Estación de Biología Tropical, "Los Tuxtlas", Veracruz, UNAM, México. Anales del Instituto Biología de la Universidad Nacional Autonoma de México 50(Series Zoología, 1):375-454.

Morón, M. A. 1984. Escarabajos, 200 millones de años de evolución. Publication 14. Instituto de Ecología, México. 130 pp.

Morón, M. A. 1987. Los estados inmaduros de Dynastes hyllus Chevrolat (Coleoptera: Melolonthidae; Dynastinae; con observaciones sobre su biologia y el crecimiento alometrico del imago. Folia Entomológica Mexicana No. 72:33-74. 
Morón, M. A. 1993. Observaciones comparativas sobre la morfología pupal de los Coleoptera Melolonthidae neotropicales. Giornale italiano di Entomologia 6:249-255.

Morón, M. A. 1995. Larva and pupa of Archedinus relictus Morón \& Krikken (Coleoptera: Melolonthidae, Trichiinae, Incaini). Pan-Pacific Entomologist 71:237-244.

Morón, M. A., and C. Deloya. 2001. Observaciones sobre el ciclo de vida de Megasoma elephas elephas (Fabricius) (Coleoptera: Melolonthidae: Dynastinae). Folia Entomológica Mexicana 40:233-244.

Morón, M. A., and J. A. Gómez-Anaya. 2002. Consideraciones sobre la categoría taxonómica de Megasoma elephas occidentalis Bolívar y Pieltain, Jiménez-Asúa y Martínez, 1963 (Coleoptera: Melolonthidae; Dynastinae). Folia Entomológica Mexicana 41:299-319.

Morón, M. A., and B. C. Ratcliffe. 1990. Descriptions of Strategus larvae with a new key to species based on the larvae (Coleoptera: Scarabaeidae: Dynastinae). Elytron 4:53-66.

Morón, M. A., B. C. Ratcliffe, and C. Deloya. 1997. Atlas de los escarabajos de México. Coleoptera Lamellicornia, Volúmen I. Familia Melolonthidae. CONABIO y Sociedad Mexicana de Entomología, México. 280 pp.

Radnai, F. 2003. Breeding Megasoma actaeon. URL: http://www.earthlife.net/insects/ megasoma.html. Page last modified on 21 June 2003. Page accessed 17 July 2003.

Ratcliffe, B. C. 2003. The dynastine scarab beetles of Costa Rica and Panama (Coleoptera: Scarabaeidae: Dynastinae). Bulletin of the University of Nebraska State Museum 16:1-506.

Ratcliffe, B. C., and F. Chalumeau. 1980. Strategus syphax (F.): a description of the third instar larva and pupa (Coleoptera: Scarabaeidae: Dynastinae). Coleopterists Bulletin 34:85-93.

Ratcliffe, B. C., and M. A. Morón. 1997. Capítulo 3. Dynastinae [pp. 53-98]. In: Atlas de los escarabajos de Mexico (Coleoptera: Lamellicornia). Vol. 1. Familia Melolonthidae (M. A. Morón, B. C. Ratcliffe, and C. Deloya, edutirs). CONABIO and Sociedad Mexicana de Entomologia, México. 280 pp.

Ritcher, P. 1966. White grubs and their allies. Oregon State University Press Corvallis, OR. 219 pp. Zahl, P. A. 1959. Giant insects of the Amazon. National Geographic Magazine 115:632-669.

(Received 13 February 2004; accepted 8 June 2004. Publication date 19 April 2005.) 